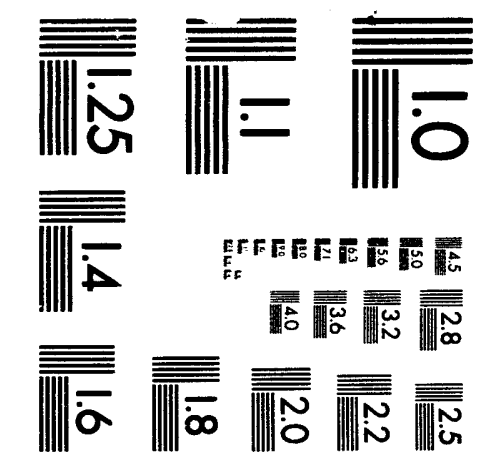



TITLE: Final Report - Development of Methods for Evaluating Options for Improving Air Quality in Santiago, Chile and its Environs

AUTHOR(S): Michael D. Williams and Michael J. Brown

SUBMITTED TO: Rich Bradley, U. S. Department of Energy

\section{DISCLAIMER}

This report was prepared as an account of work sponsored by an agency of the United States Government. Neither the United States Government nor any agency thereof, nor any of their employees, makes any warranty, express or implied, or assumes any legal liability or responsibility for the accuracy, completeness, or usefulness of any information, apparatus, product, or process disclosed, or represents that its use would not infringe privately owned rights. Reference herein to any specific commercial product, process, or service by trade name, trademark, manufacturer, or otherwise does not necessarily constitute or imply its endorsement, recommendation, or favoring by the United States Government or any agency thereof. The views and opinions of authors expressed herein do not necessarily state or reflect those of the United States Government or any agency thereof. 


\section{ADEPT}

Final Report: Summary

Project Title: Development of Methods for Evaluating Options for Improving the Air Quality in Santiago, Chile and its Environs.

Principal Investigator: Michael D. Williams

\section{Activities/Milestones:}

1. Obtained meteorological, topological, emission, and air quality data information.

2. Prepared preliminary simulations of meteorology and air dispersion in both regions of interest. The meteorological input was based on long-term climatological mean conditions. The sensitivity of the model was investigated.

3. Presented a paper to the CONGRESO INTERNACIONAL DE INGENIERIA DE MINAS (in Spanish) at Copiapó, Chile.

4. Delivered models and sample input and output data to Chilean colleagues.

5. Prepared a second set of simulations using measured upper air data and compared model results to measurements.

\section{Other Activities: Travel}

The first trip was to Santiago and the site of the Ventanas Smelter.

The second trip was to Santiago and Copiapo, Chile from August 15-20. Tite cost was about $\$ 3.5 \mathrm{k}$.

\section{Presentations:}

Preliminary Application of the HOTMAC-RAPTAD Modeling System to ditle an Smelters, by Michael D. Williams, Michael J. Brown, and Luis Matamala.

Presented to the CONGRESO INTERNACIONAL DE INGENIERIA DE MIPAS in Copiap6, Chile from August 15-20. 


\title{
FINAL REPORT \\ Development of Methods for Evaluating Options for Improving the Air Quality in Santiago, Chile and its Environs
}

\author{
Michael D. Williams and Michael J. Brown \\ Energy and Environmental Assessment \\ Los Alamos National Laboratory \\ October 1993
}

\section{A. INTRODUCTION}

Santiago, Chile has a serious air pollution problem. Aerosols reach very high levels and ozone exceeds US ambient standards on over 100 days a year. Chileans are very concerned about the poor air quality of Santiago and they are also concerned about the effect of emissions from their copper smelters both near Santiago and at other sites. Officials from both the Santiago metropolitan air quality commission (La Comisión Especial de Descontaminación de le Región Metropolitana) and a government owned copper development company (La Empresa Nacional de Minería (ENAMI)) have asked our assistance to deal with the air quality problems in the city and associated with smelter emissions. This report describes our first steps in that effort.

Santiago lies in a valley between a small coastal range to the west and the towering Andes to the east. Air motion is greatly affected by the major topographical features which include the Pacific Ocean, the coastal range, and the Andes. The topography and a paucity of measured data pose a significant challenge to air quality modelers.

In this first year of work we concentrated on gathering information on the meteorology, topography, and air quality of the metropolitan region. In addition we examined two smelter sites and applied models to them to help our understanding and to provide assistance to ENAMI. One smelter, Ventanas, was located on the Pacific coast to the northwest of Santiago, while the other, Paipote, was located several hundred kilometers to the north. The Ventanas emissions may potentially affect Santiago air quality. Several advantages of working with the smelters in the first phase of the project are: (1) there is more monitoring in the vicinity of the smelters, (2) the development of a useful emission inventory is easier, (3) they pose a simpler problem of immediate interest whose resolution will provide an early benefit to our Chilean colleagues, and (4) we gain important experience as we prepare to delve deeper into Santiago's air pollution problems. 


\section{B. MODEL DESCRIPTION}

Frequently, air quality modeling relies on simplistic assumptions about the winds and transport parameters. For example, in some simple situations a wind measured at a single site will be taken as representative of the winds throughout the region of interest. However, if the terrain is complex such simple assumptions are of little use. In complex terrain, measurements are frequently representative of only very small volumes surrounding the site of the measurement. We have developed a modeling approach for complex terrain which uses a meteorological model (HOTMAC) to compute a full, three-dimensional time-dependent wind field. The output from the meteorological code is then used to drive a random particle dispersion code (RAPTAD). The intent of the approach is to represent the important physics in detail rather than relying on a dense system of measurements to provide the physics from the measurements alone.

HOTMAC is a three-dimensional time-dependent mesoscale meteorological model developed by Yamada (1985). It uses the hydrostatic approximation and a terrain following coordinate system. HOTMAC solves conservation relations for the horizontal wind components, potential temperature, moisture, turbulent kinetic energy, and the turbulence length scale. HOTMAC describes advection, Coriolis effects, turbulent transfer of heat, momentum, and moisture. It also includes solar and terrestrial radiation effects, turbulent history effects, and drag and radiation effects of forest canopies. The development of the equations is described by Yamada (1981) and Mellor and Yamada (1982). The lower boundary conditions are defined by a surface energy balance and similarity theory. The soil heat flux is obtained by solving a heat conduction equation in the soil which ignores lateral heat transfer.

Mesoscale models are designed for circumstances in which the local terrain influences are significant and make the meteorology more predictable than might otherwise be the case. The two Chilean smelters which we studied, Ventanas near Valparaiso and Hernán Videla Lira near Paipote, both represent applications with major terrain influences. At Hernán Videla Lira, there are steep slopes nearby and the whole area is dominated by a linked sea-breeze and mountain-valley wind system. At Ventanas the nearby Pacific produces a strong sea-breeze influence.

RAPTAD is a Monte-Carlo dispersion and transport code, developed by Yamada (1988). Pseudo-particles are transported with instantaneous velocities that include the mean wind field and the turbulent velocities. The turbulent velocity is randomly generated with a Gaussian distribution and standard deviation equal to that of the wind at the particle location. The location of each pseudo-particle represents the center of mass of a concentration distribution for each puff. The total concentration at any point is obtained by adding the concentration contributions of each puff at that point (a kernel method). The Monte Carlo kernel method requires that a functional form for the distribution kernel be chosen and that parameters that describe the width, breadth, and depth of the distribution be calculated. The approach used here is to assume a Gaussian distribution where 
variances are determined from the time integration of the velocity variances encountered over the history of the puff. The variances are estimated based on the random force theory of turbulent diffusion (Lee and Stone, 1982).

The system has many advantages for applications involving complex terrain. The use of a higher-order turbulence model means that there are three-dimensional time-dependent wind fields and turbulence fields available for the representation of dispersion and transport. Transport can be treated in more detail because important terrain influences are represented in both the mean fields and the turbulence fields. The RAPTAD model works well in situations where the wind directions change with height, whereas normal Gaussian puff models are inadequate. Other random particle codes which calculate concentrations by counting random particles in cells have significant deficiencies. If the cell size is too small the concentrations will be very noisy with some cells having no particles and thus no concentrations while an adjacent cell may have one or two particles in its small volume and thus have very large concentrations. If the cells are too large, the concentrations will be smeared out in an unrealistic fashion. The kernel system as used by RAPTAD avoids this problem because the pollution associaied with a particle is not concentrated at a point but extends over a volume surrounding a point. The volume around the point is calculated based on ihe turbulence history of the particle.

\section{DATA SOURCES}

There were two kinds of topographical data available for the modeling. In the vicinity of each smelter, information had been extracted from topographical maps to support modeling efforts. In addition, a database constructed by the US Army provides topography which covers a great deal of Chile and provides elevation contours at 1000 foot intervals. These data would be too coarse to rely upon in the immediate vicinity of the sources. However, it can be used to represent the effects of larger scale features outside of the immediate area of interest.

For the purposes of this work, large scale domains on the order of 200 to 300 kilometer $(\mathrm{km})$ were needed to properly represent the major terrain influences (e.g., the Pacific Ocean and the crest of the Andes). In the case of the Ventanas site, the region was made large enough to include Santiago and an area south of Santiago which has another smelter of potential significance. In the vicinity of the smelters high resolution was required. For each site we combined the local terrain with the larger-scale terrain and constructed three computational grids. In the case of Paipote, three grids were used with an outer mesh size of $9 \mathrm{~km}$, an intermediate mesh size of $3 \mathrm{~km}$ and

an innermost mesh size of $1 \mathrm{~km}$. In the case of Ventanas the mesh sizes were $18 \mathrm{~km}, 6 \mathrm{~km}$, and 2 $\mathrm{km}$.

Initial simulations were made with climatological data as input. Later on, we obtained and analyzed meteorological data from Quinteros which is the closest upper air meteorological station 
to both Santiago and the Ventanas smelter. This database was bought from the National Climatic Data Center in Asheville. We also bought data for Antofagasta, a site in the north of the country, although that data has not been used in any of the simulations. Figure $\mathrm{C} 1$ displays a map of Chile with the locations of Quinteros, Santiago, Paipote, and Antofagasta. At the Paipote site we also had meteorological data from a tower on a small hill near the smelter and air quality measurements from four sites nearby.

\section{MODEL APPLICATION}

The summer months were chosen for the first model applications to help support the field experiments which will take place in December at the Ventanas site. At Paipote we selected July 7,1992 , a day which had high $\mathrm{SO}_{2}$ concentrations at a key monitoring site in the little agricultural community of Tierra Amarilla. At the Paipote site stack top and fugitive emissions of $\mathrm{SO}_{2}$ were modeled, while at Ventanas only stack top emissions were modeled.

The model uses measured winds averaged over the lowest 500 meters and the winds at 1500 meters and 3000 meters above sea level as input. For the Ventanas site, we used the upper air soundings from Quinteros, because the tower data has not yet been assembled into a data base. Unfortunately, the Quinteros soundings usually reported wind data at very few heights so that the 500 meter averages represented, at best, crude approximations.

In the case of Paipote, the Quinteros winds were used for the 1500 and 3000 meter levels while the local tower was used as representative of the lowest 500 meter winds. There are two deficiencies with this procedure: (1) the Quinteros winds are measured at a site which is several hundred $\mathrm{km}$ from Paipote and (2) the tower winds are measured at a much lower height than 500 meters and do not necessarily represent an average wind. Furthermore, a 10 meter tower near Paipote was used rather than the meteorological tower near the smelter. We could improve this simulation by: 1) using winds interpolated between Quinteros and Antofagasta; 2) modifying the input data to treat the tower data as representative of the lower 200 meters rather than 500 meters; and 3) by using the meteorological tower rather than the 10 meter tower at the sampling site. The Antofagasta station is a few hundred $\mathrm{km}$ to the north of Paipote.

In both cases the model is first run with very light winds near the surface and typical upper level winds. This step is necessary to obtain the local wind corrections which are then subtracted from the measured low level (lowest 500 meters) to obtain the large-scale driving winds. Measured winds are then included at whatever intervals are available. In the case of Paipote, hourly measured winds were available, but the upper level winds were only available at intervals of 12 hours. Interpolated upper level winds were used with the hourly tower measurements. 


\section{E. MODEL RESULTS - PAIPOTE}

Figure E1 shows the calculated winds on the largest grid at 3 am of July $7^{\text {th }}, 1992$. The large blue area is the lowest contour and it was not set at sea-level so that the area includes both land and water. The medium-sized box includes the intermediate grid with a resolution of $3 \mathrm{~km}$, while the smallest box represents the fine grid domain with a resolution of $1 \mathrm{~km}$. The wind vector arrow in the lower right represents a speed of $10 \mathrm{~m} / \mathrm{s}$. The red letters represent the monitoring stations: C (Copiapó), S (San Fernando), P (Paipote), M (the meteorological tower near the plant) and $\mathrm{T}$ (Tierra Amarilla). The winds are mostly downhill and offshore, as would be expected when cold air flows downhill and pushes under the warmer air over the ocean. Figure E2 shows a similar plot for 4 PM when the winds have reversed and there is flow up the valleys and on-shore. The

Incas used to do their smelting of copper in the afternoon to take advantage of these stronger winds.

Figure E3 shows the calculated winds on the intermediate grid at 3 am. The winds are downhill and offshore and very light in the valley bottoms and lowlands. The smaller box represents the fine grid domain. At this time of the day large concentrations would be expected in the valley bottom near the Paipote station. Figure E4 shows the winds at noon, when we have a much different pattern; it is about this time that high concentrations occur at $\mathrm{P}$ and $\mathrm{T}$. Figure E5 shows the calculated winds at $4 \mathrm{pm}$, when the pollution levels are much lower.

Figure E6 shows the calculated winds on the fine-grid domain at $3 \mathrm{am}$. In this figure the red dots or arrows (hard to see) show the measured winds in comparison to the model results. Both the measured and modeled winds are weak, but the model winds appear to be somewhat stronger. We also note that frequently the modeled winds change rapidly with distance as we move from the mountain slopes to the valley floor. We should note that the averaged terrain tends to average the slopes and the valley and shrink the width of the valley. The model resolution also tends to smear out the distinction between mountain slopes and the valley floor.

Figure E7 shows the comparison between calculated winds and measured winds at noon. One of the most critical areas is the agricultural community of Tierra Amarilla (T). We can see that a trajectory starting near $P$ on the west side of the valley would carry material to $T$, but a trajectory starting a little further east will carry the material to the southeast and miss T. Figure E8 shows the area of concern in more detail. When attempts were made to model this situation by our Chilean colleagues with a diagnostic wind model which interpolates the winds from $\mathrm{C}, \mathrm{S}, \mathrm{P}, \mathrm{M}$, and $\mathrm{T}$ in a mass consistent fashion, the results were disappointing. It is clear from our model results that transport to $\mathrm{T}$ is going to be very sensitive to the terrain used in the model. A broader valley would allow more trajectories toward the south from the vicinity of the smelter.

Figure E9 shows the winds at $4 \mathrm{pm}$ and we can see that pollution from the vicinity of the smelter is more likely to go the southeast and the higher wind speeds will disperse it more. Figure 
E10 displays a comparison between the modeled and measured winds for each hour on July $7^{\text {th }}$, 1992. Generally, the wind speeds show similar patterns, although the measurements give lighter winds at night. Again it's clear why the Incans chose to do their smelting in the afternoun. Figure E11 shows a similar comparison for wind directions. The model tends to do well during the late mornings and afternoons, but it has more trouble representing the very light nighttime winds. Note that some of the biggest discrepancies are actually less than they appear. For example the measured wind direction of -120 degrees near midnight at $P$ corresponds to 240 degrees, which is much closer to the modeled value of 150 degrees.

Figure E12 shows a comparison between modeled $\mathrm{SO}_{2}$ concentrations and measured ones for all the stations except $\mathrm{M}$ which does not monitor $\mathrm{SO}_{2}$. The modeled peak in the early morning at $\mathrm{P}$ is produced by fugitive emissions which are taken as $5 \%$ of the total emissions. The timing is off somewhat but the magnitude is very similar to the measured concentrations. The concentrations are reported in parts per million (ppm), so that relatively high concentrations are occurring. In comparison the US 3 hour standard is $0.5 \mathrm{ppm}$ while the 24 hour average health based standard is $0.14 \mathrm{ppm}$. The modeled peaks near noon at $\mathrm{P}$ and $\mathrm{T}$ are both from the stack emissions. In both cases the peaks are underestimated.

Figure E13 shows the comparison for July $8^{\text {th }}, 1992$. In this case the measurements at $T$ show concentrations which are half of those on the $7^{\text {th }}$ and the model shows no impact.

Overall these preliminary simulations suggest that the model may be able to produce a good description of the observed behavior of pollution from Chilean copper smelters. There are a number of things which could be improved including: (1) a better representation of the terrain, (2) a better representation of surface characteristics, (3) the use of data from the meteorological tower, rather than the 10 meter tower at the $\mathrm{SO}_{2}$ sampling site, and (4) a more accurate inclusion of measured winds into the simulations. We have mentioned how the valleys are artificially narrowed by the procedures for putting the terrain into the model. Better representations of the terrain could easily be developed. In the context of surface characteristics, much of the valley bottoms are occupied by vineyards which are ir rigated. This means that the valleys should have much higher soil moisture than the surrounding countryside. In this simulation we considered only a wet ocean and very dry land. It would not be difficult to put in wet soils in the irrigated portions of the valley bottoms. The increased soil moisture would produce higher temperatures at night and lower ones during the day, which would influence the local winds.

The 10 meter tower winds were taken as representative of winds over the lower 500 meters of the atmosphere which is incorrect. We could make simulations using the meteorological tower winds and assume that they represent the average of winds over the lowest 200 meters, which might change the wind behavior in the critical region near the smelter. In the long term ENAMI 
is purchasing a sodar which could provide much better winds for the model.

\section{F. MODEL RESULTS - VENTANAS}

\section{HOTMAC Sensitivity Tests.}

As part of the first phase of the Chile Air Quality Program, we tested the sensitivity of the HOTMAC model output to the domain size and several different input parameters. The varied input parameters included start time and initial land-surface temperature. The east-west domain size was changed so as to include varying amounts of ocean and mountain grid cells. We compared and contrasted the horizontal vector wind, vertical velocity, temperature and water vapor fields that were computed by the model in 48 to 72 hour simulations. We will only give a brief summary of the results here, but an internal report containing further details can be obtained directly from the authors.

The simulations began on Dec. 10 (Julian day 345). The sensitivity tests were performed on a double-nested mesh surrounding the Ventanas smelter. The location, number of grids, and grid resolution for the three mesh types are given in Table F1. Fifteen grids extended from the surface

Table F1: Horizontal grid parameters

\begin{tabular}{|c|c|c|c|c|}
\hline mesh type & $\begin{array}{c}\text { SW corner } \\
(\mathbf{u t m}, \mathbf{k m})\end{array}$ & $\begin{array}{c}\text { grid size } \\
\mathbf{( k m )}\end{array}$ & $\begin{array}{c}\text { no. of grids } \\
\text { E-W dir. }\end{array}$ & $\begin{array}{c}\text { no. of grids } \\
\text { N-S dir. }\end{array}$ \\
\hline coarse & 209,6189 & 18 & 10 & 14 \\
\hline medium & 245,6297 & 6 & 15 & 21 \\
\hline fine & 263,6351 & 2 & 12 & 18 \\
\hline
\end{tabular}

to $4000 \mathrm{~m}$ above the surface. Boundary and initial conditions for the meteorological variables were estimated using climatological values (Schwerdtfeger, 1976): the upper-level winds were set to $2 \mathrm{~m} / \mathrm{s}$ coming out of the southwest; the potential temperature lapse rate was specified as $+.011^{\circ} \mathrm{C} / \mathrm{m}$ below $1250 \mathrm{~m}$ and $+.004^{\circ} \mathrm{C} / \mathrm{m}$ above; and the relative humidity was assigned a value of 0.83 at the surface and decreased to 0.20 at the top of the domain. The input parameters were assumed to be invariant in the horizontal direction.

In order to test the effect of the temperature difference between the ocean and the land, we changed the initial land temperature from $16^{\circ} \mathrm{C}$ to $12^{\circ} \mathrm{C}$, while keeping the ocean temperature at $15^{\circ} \mathrm{C}$. In both simulations, the velocity fields and the shape of the temperature contour fields were nearly identical (except near the coast where the temperature gradient was, of course, stronger in the latter case). The difference in land-surface temperatures remained at $4^{\circ} \mathrm{C}$ throughout the entire simulation. However, the temperature at a specific time of day changed until a diurnal steady-state was achieved. Hence, an accurate prescription of the initial land-surface temperature 
appears important for modeling the absolute value of temperature, but is relatively unimportant when one is concerned with the prediction of the velocity field.

The simulation start time affects the amount of time that it takes for the model-computed meteorological variables to reach a diurnal steady state. Figure F1 shows that the temperature, wind speed, and wind direction reach a diurnal steady state shortly after sunrise. When the simulation was started in the evening hours, we found that the first night of modeled meteorological fields were not in equilibrium. It appears that the strength of the convective forcing due to solar heating regulates the nature of the flow field throughout the entire 24 hour diurnal cycle and reduces the impact of the initial conditions. In order to reduce computer simulation time, we recommend that the computer simulation begin shortly before sunrise.

We have included the ocean and the Andes mountains in our modeling domain in order to account for the mesoscale features of the flow. We have run two simulations in which we have subtracted thirty-six kilometers ( 2 grids) of ocean and added eighteen kilometers ( 1 grid) of mountain terrain to the outer grid to test whether or not we have included enough ocean and mountain terrain in the computational domain. Comparison of simulations with differing areas of ocean showed that the modeled winds were nearly identical, except for a slightly larger on-shore component during the daytime for the case with more ocean. The biggest differences were found in the water vapor fields, which indicated that more water vapor was present in the air and that a larger amount had been advected inland when more ocean was included in the domain. Although the effect on the modeled wind field is small, we recommend including the larger area of ocean in the computational domain since the pollution source at Ventanas is close to the coast.

Because the mountains on the eastern edge of the computational domain are, in general, still rising, there is a possibility that the simulated flow field in the interior of the domain could be sensitive to the slope-flow boundary condition. We have added eighteen kilometers of terrain with smaller elevations to the outer grid on the eastern boundary in order that the slope-flow boundary condition will primarily affect the flow to the east of the newly-created mountain ridge and that the slope-flow on the western side will be completely determined from the governing equations. We found that the modeled horizontal wind vector fields were very similar with and without the added mountain terrain. Differences between the two cases were most notable in the vertical velocity contour fields. In particular, the maximum vertical velocities over the mountains during the daytime were from 10 to 30 percent larger in the simulation with the extra mountain terrain.

In summary, the modeled wind fields were not terribly sensitive to the variation of the input parameters and domain configuration. Since the added ocean terrain slightly affected the wind field near the coast and because the Ventanas smelter is near the coast, we will include the extra two grids of ocean in our computational domain. Likewise, since the effect of the added mountain terrain was localized to the eastern side of the computational domain, we will not include the extra grid in our computational domain (moreover, we do not have elevation data there).

The start time most influenced the time required for the model to reach a diurnal steady-state. It appears that a start time just prior to sunrise may result in the shortest "spin-up" time. We also found that the initial land-sea surface temperature difference did not significantly affect the flow 
fields. However, we saw that the steady-state temperature for a particular hour of the day was sensitive to the start time. Hence, if possible, it would be beneficial to include an initial temperature field that is a function of $\mathrm{x}$ and $\mathrm{y}$, rather than assuming a horizontally homogeneous temperature field based on the temperature at one particular location.

\section{Meteorological Simulations.}

In this section, we will present horizontal wind vector fields produced by the HOTMAC model during a seventy-two hour simulation. Comparisons with observations will not be presented as field measurements are not yet available. The initial profiles of wind speed, wind direction, potential temperature, and relative humidity are shown in fig. F2. The initial conditions and the large-scale forcing winds were obtained from the upper air soundings at Quinteros. We should point out that the averaged large-scale wind in the $0-500 \mathrm{~m}$ layer has been estimated from subtracting off the "local" wind (the wind computed by the model using minimal large-scale forcing) from the measured wind (which presumably includes the large-scale and local-scale forcings).

The computational domain, described in Table F1, is depicted in fig. F3. The intermediate and inner nested grids are shown as yellow rectangles. The terrain contours on the outer grid are spaced at $400 \mathrm{~m}$ intervals. The Ventanas site is denoted by the letter $\mathrm{X}$. The simulation was started at 8:00 am local standard time on Dec. 10. Figure F3 illustrates the typical daytime flow pattern at a ten meter height. The winds are predominately directed up the mountain slopes, a result of the rising buoyant motion induced by the warmer land surface. Interestingly, strong winds appear to the east of Ventanas, apparently due to the funneling effect of the valley topography. At the latitude of Santiago, we notice that the inland flow is directed towards the north and south up the local mountain features, resulting in a region of divergence and hence slower winds. Also of note are the small easterly winds found over the ocean. It may be that the local wind correction combined with the crude averaring of the measured winds in the 0-500 m layer are responsible for the unexpected easterly flow.

Figure F4 illustrates the typical night time flow pattern at a ten meter height. The winds are nearly zero and some are directed downslope or towards the ocean. The radiative cooling of the land surface apparently is not strong enough to overcome the weak large-scale southwesterly flow.

Details of the flow in and around the Ventanas site can be seen by looking at the intermediate grid. Figure F5 depicts the typical daytime flow pattern $a^{+}$a ten meter height. On the western half of the domain, where the terrain is relatively flat, the flow is predominantly directed onshore. On the eastern half of the domain, the effect of the small coastal mountains can be clearly seen. The flow is everywhere directed upslope, resulting in winds directed at all angles. Of interest to modeling air pollution from Ventanas is the region to the east between the mountain peaks (utm coordinates of $[310,6365])$. Here, a plume that has been transported by the westerly flow will, depending on its precise location, either be directed towards the north or the south.

The flow pattern at night in the intermediate grid is very similar to that shown in the outer grid 
(fig. F4): winds are nearly zero and some are directed downslope or towards the ocean. The inner grid shows strong winds going from east to west during the daytime and calm conditions at night. Figure F6 shows the daytime winds at a height of $229 \mathrm{~m}$. The wind field at this height is important because the pollutant plume from the Ventanas stack will typically rise to a height of 200 to $350 \mathrm{~m}$. One can see that the winds are not as strong as those at a height of ten meters (fig. F3). Winds over the ocean are directed to the west, while winds at the coastline are very light. At night, the winds are nearly zero everywhere.

\section{Pollution dispersion simulations.}

Using the RAPTAD model, the dispersion of the plume from the elevated stack at Ventanas was simulated. The meteorological input parameters (wind, turbulence, and temperature fields) were obtained from the HOTMAC simulations described in the previous section. The stack parameters are described in Table F2. For the purpose of simulation, we have combined the two

Table F2: Stack parameters

\begin{tabular}{|c|c|c|c|}
\hline parameter & stack \#1 & stack \#2 & combined stack \\
\hline stack height $(\mathrm{m})$ & 155 & 155 & 155 \\
\hline stack diameter $(\mathrm{m})$ & 2 & 3 & 3.4 \\
\hline temperature $(\mathrm{K})$ & 530 & 545 & 537.9 \\
\hline vertical velocity $(\mathrm{m} / \mathrm{s})$ & 6 & 3 & 4.4 \\
\hline source strength $(\mathrm{g} / \mathrm{s})$ & 2395 & 1551 & 3946 \\
\hline
\end{tabular}

elevated stacks at Ventanas into one combined source by assuming that the mass and volume flow rates and the buoyancy flux were additive quantities. Plume rise ranged from $100 \mathrm{~m}$ at night to $250 \mathrm{~m}$ during the day. We have not included the fugitive emissions in the present simulation.

The simulation was started at 10:00 am on Dec. 10. One particle was released every forty seconds from the stack. Figures F7a-h show eight snapshots of particle positions at different times during a thirty-six hour simulation. The black dots represent the center of the pollutant parcels. The size and height of each parcel are not depicted. Note: for accurate concentration computations a larger number of parcels must be released per unit time.

Three hours after the start of the plume simulation (fig. F7a), the pollutants have traveled over fifty kilometers to the east due to the strong westerly winds. Just west of the coastal mountains, the plume bends slightly northward in response to the southwesterly winds. By 17:00 hours, the plume has traveled into the valley region to the east of the coastal range (fig. F7b). We also see that just before the coastal range some parcels have drifted southward (figs. F7b and c), perhaps resulting from the elevated plume impinging upon the land-surface boundary layer, which is growing in height with distance from the coast. 
During the night, the plume is narrow near the source due to the suppression of turbulence by the stable stratification (figs. F7c and d). However, the particles have spread out considerably in the valley beyond the coastal mountains, most likely due to mountain-induced turbulence.

A very interesting event occurs as a result of the very light easterly winds that develop at the end of the night. In figs. F7d and e, one can see that the plume has traveled to the west of the source. The plume remains narrow and elevated due to the stable stratification. After the sun rises, the heating of the land surface results in a strong westerly flow and increased turbulence levels. Figures F7f and $g$ show that the pollution emitted during the night reverses direction and travels to the east as a large cloud. As a result of the night time emissions, the area affected by the Ventanas stack during the daytime is much larger (compare figs. F7a and h). Therefore, we strongly recommend that the RAPTAD model be run at least overnight in order to obtain reliable computations of daytime concentrations.

\section{G. SUMMARY}

We have presented model computations of air flow and pollution dispersion in the vicinity of the Paipote and Ventanas smelters using the HOTMAC and RAPTAD models. A sensitivity analysis was performed in which it was determined that the domain size was sufficient to capture the relevant mesoscale flow features. Additionally, we found that an early morning simulation start time gave the shortest model "spin-up" time.

In the Paipote simulation, classic exainples of the day time upslope flow and night time downslope flow were modeled. Comparison of model-computed and observed wind speeds and wind directions showed similar trends. We also found that in the vicinity of the smelter the wind direction changed significantly as function of location due to the valley topography. Hence, comparisons of modeled and observed concentrations were only marginal, but there is good reason to believe that a better prescription of the emissions and the local topography would improve the comparison.

In the Ventanas simulation, the computer model produced day time winds that were strong and dominated by the mountain terrain. At night, the computed winds were nearly zero. Our simulation of plume dispersion showed little mixing of the plume during the night. As a consequence, the night time emissions were mixed down to the ground during the day time resulting in a much larger area affected by the smelter. We also found that mixing was enhanced on the eastern side of the coastal mountains. Field measurements were not available for comparison.

In conclusion, the major accomplishments in the first phase of the Santiago Air Quality Project include:

1) the processing of meteorological, topological, emission, and air quality data for use in the HOTMAC and RAPTAD models;

2) a sensitivity analysis of the HOTMAC model to domain size and several input parameters;

3) a successful simulation of the mesoscale flow features (e.g., sea and mountain breezes): 
4) the discovery of several important local-scale meteorological and air pollution dispersion features (e.g., sensitivity of wind direction to valley topography near Paipote and the dense pollutant cloud that may form at night above the Ventanas stack and mix to the ground during the day time); and

5) a delivery of models, sample input, and sample output data to our Chilean colleagues.

Acknowledgments. We wish to thank Mr. Rick Bradley and the US Department of Energy for their support of this project. The help of Luis Matamala of CIMM (Centro de Investigación Minería y Metalurgica) and John O'Brien and Alejandro Diez of ENAMI was critical to the success of the project. In addition, Mr. Juan Escudero Ortúzar of the Comisión Especial de Descontaminación was also very helpful. At Los Alamos National Laboratory, Mr. Jorge Roman provided key assistance with topographical databases.

\section{REFERENCES}

Lee, J. T., and G. L. Stone, 1982, "The Use of Eulerian Initial Conditions in a Lagrangian Model of Turbulent Diffusion", Los Alamos National Laboratory, LA-UR-82-3034, Los Alamos, NM. Mellor, G. I. and T. Yamada, 1982, "Development of a Turbulence Closure Model for Geophysical Fluid Problems", Rev.Geophys. Space Phys., vol 20, pp 851-875.

Schwerdtfeger, W., ed., 1976: Climates of Central and South America, vol. 12, Elsevier Scientific Publishing Company, New York.

Yamada, T., 1981, “A Numerical Simulation of Nocturnal Drainage Flow”, J. Meteor. Soc., Japan, vol 59, pp 108-122.

Yamada, T., 1985, "Numerical Simulation of the Night 2 Data of the 1980 ASCOT Experiments in the California 'Geysers Area", Archives for Meteorology, Geophysics, and Bioclimatology, Ser. A34, pp 223-247.

Yamada, T. and S. Bunker, 1988, "Development of a Nested Grid, Second Moment Turbulence Closure Model and Application to the 1982 ASCOT Brush Creek Data Simulation", J. Appl. Meteor., vol 27, pp 562-578. 


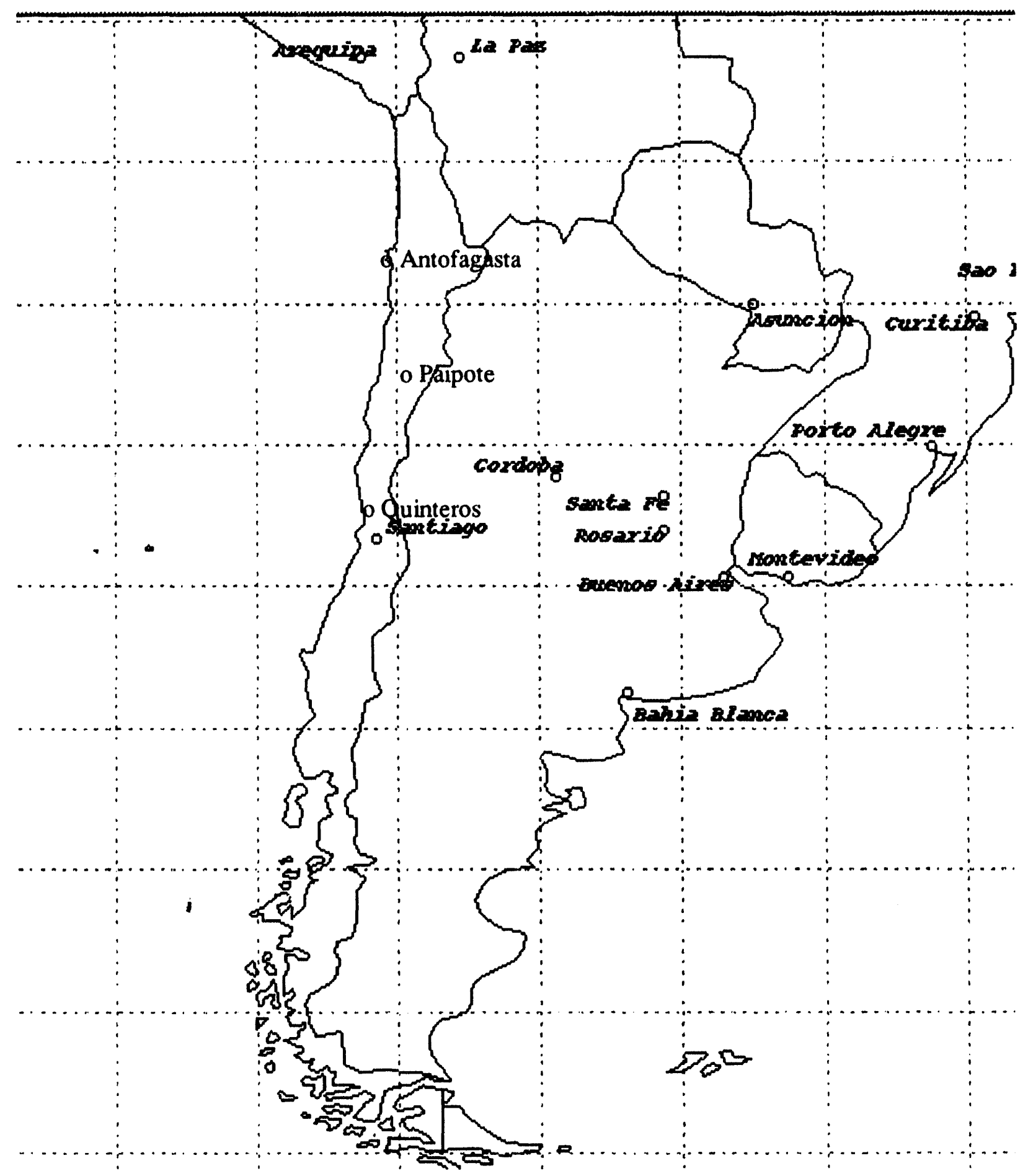

Figure C1. Map of Chile with Santiago and other locations of major interest in Chile. 


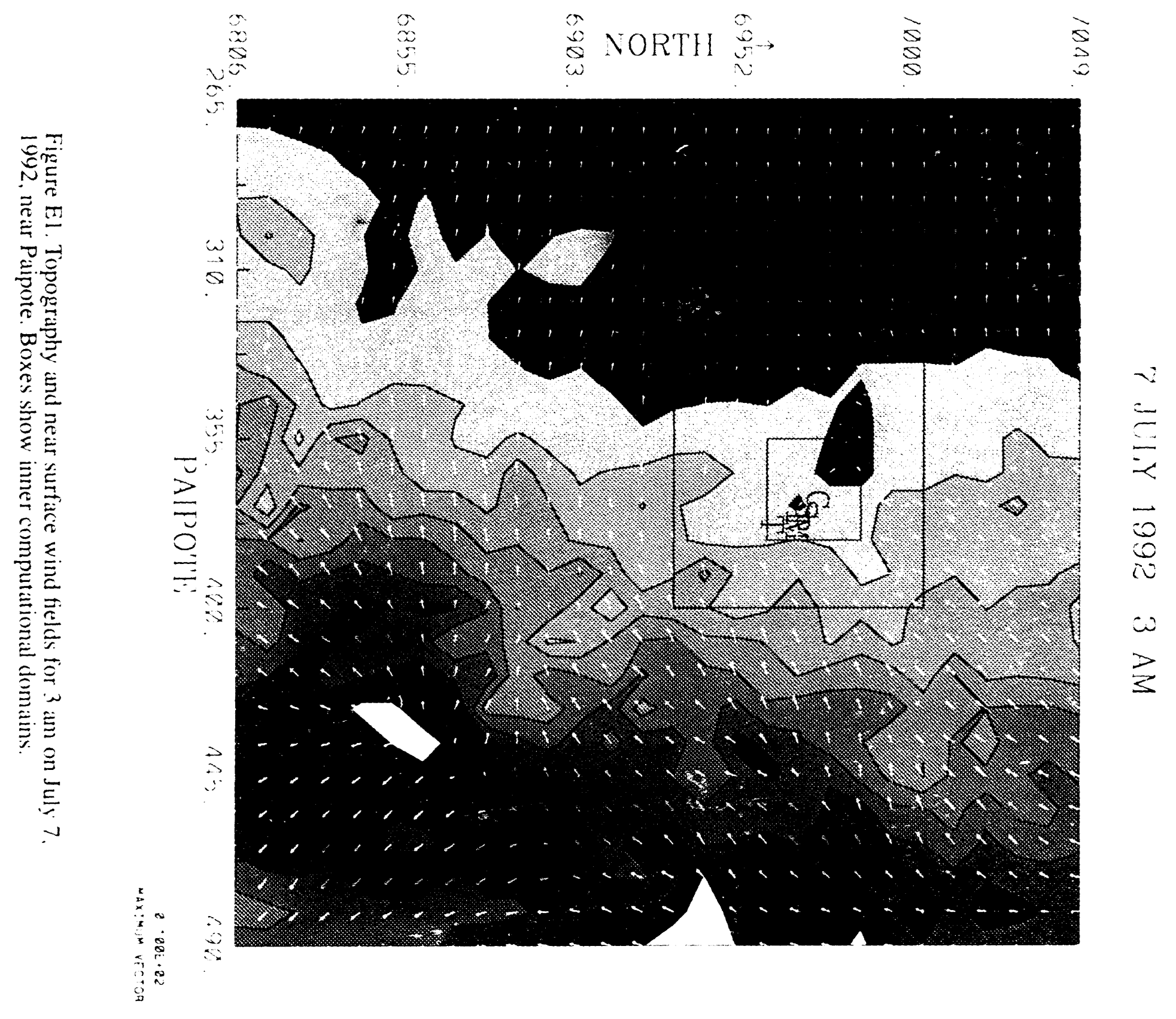




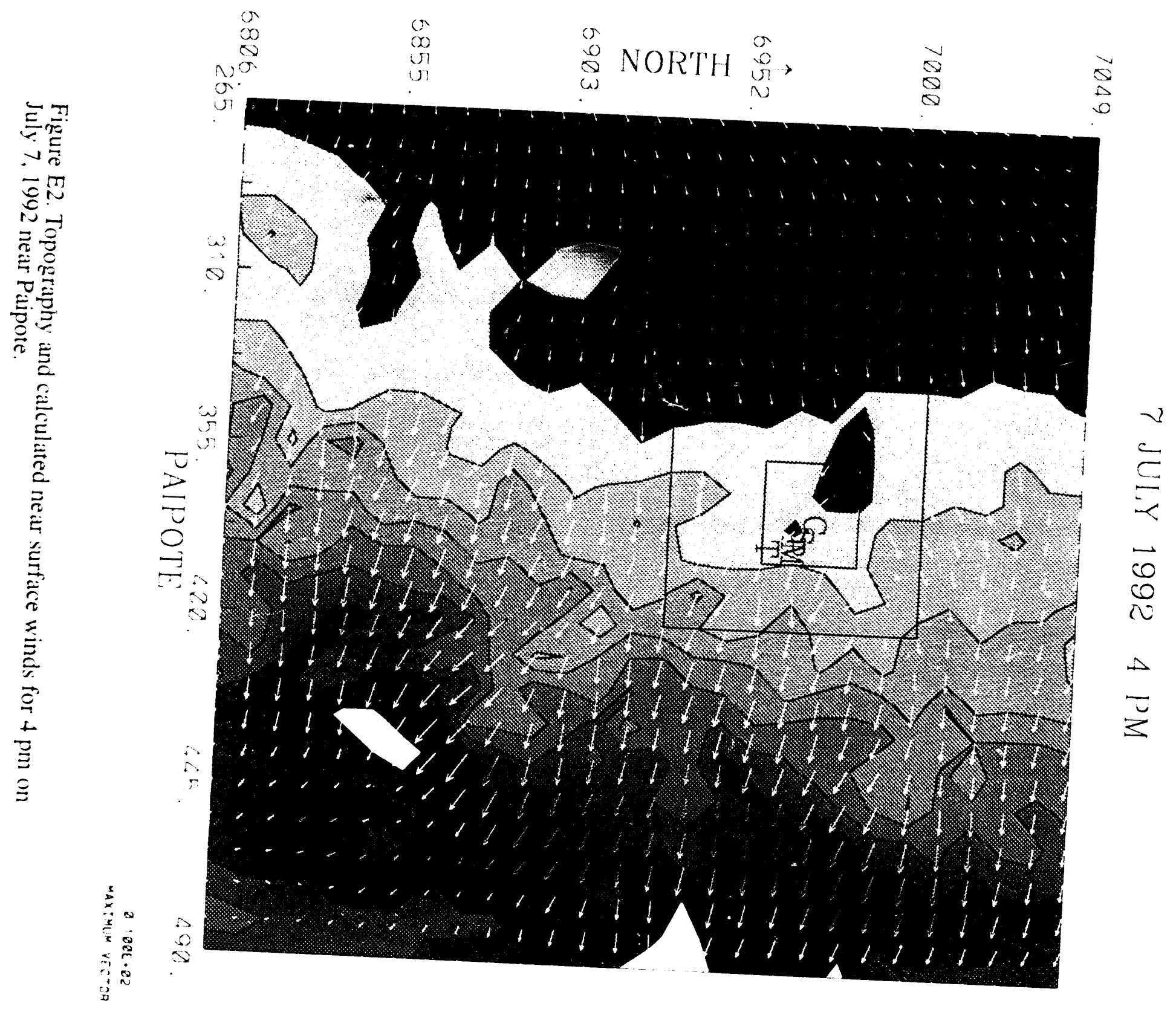




\section{JULY 19923 AM}

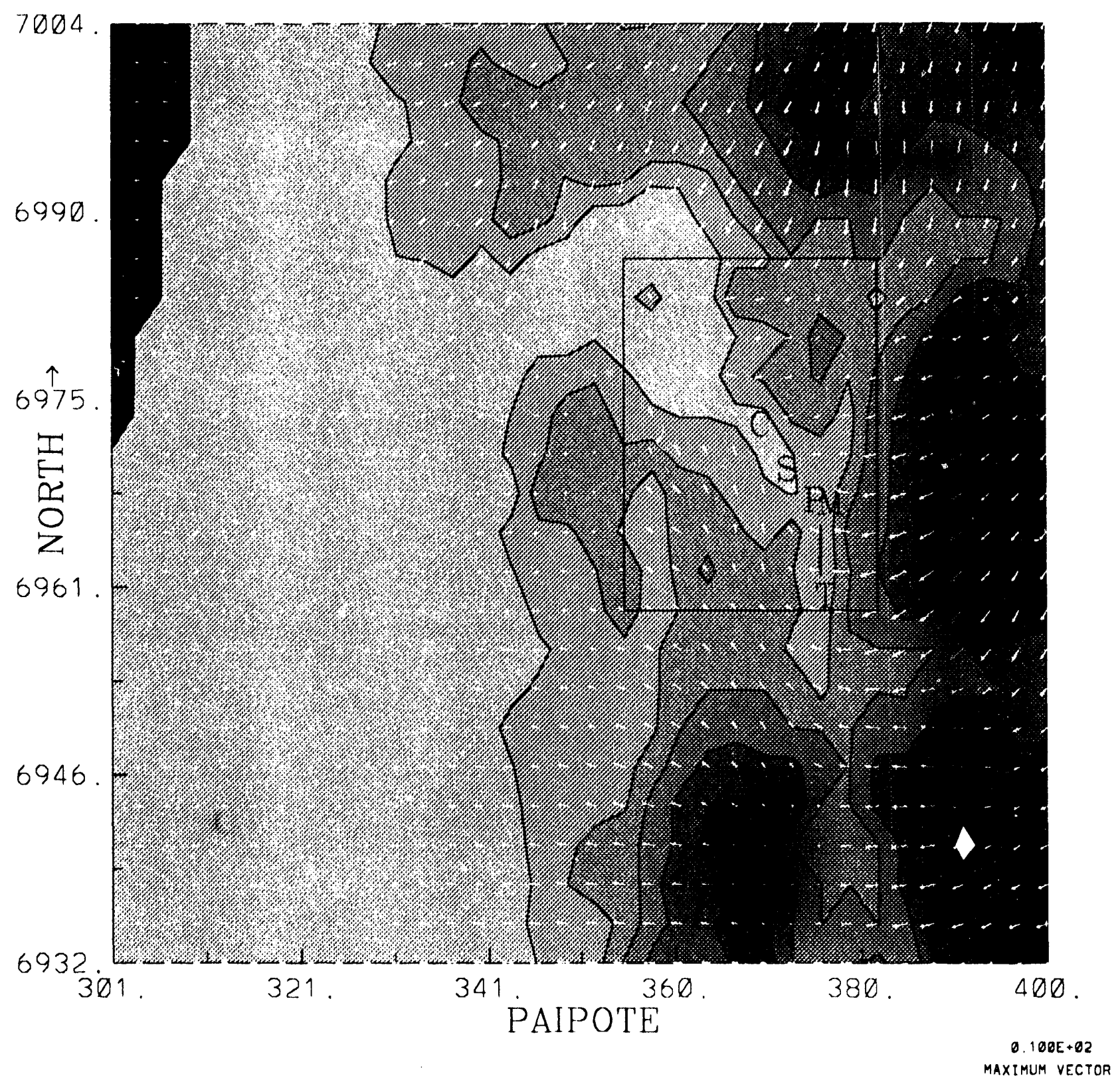

Figure E3. Simulated near surface winds at 3 am on July 7,1992 near Paipote. Red symbols denote monitoring locations. 


\section{JULY 199212 PM}

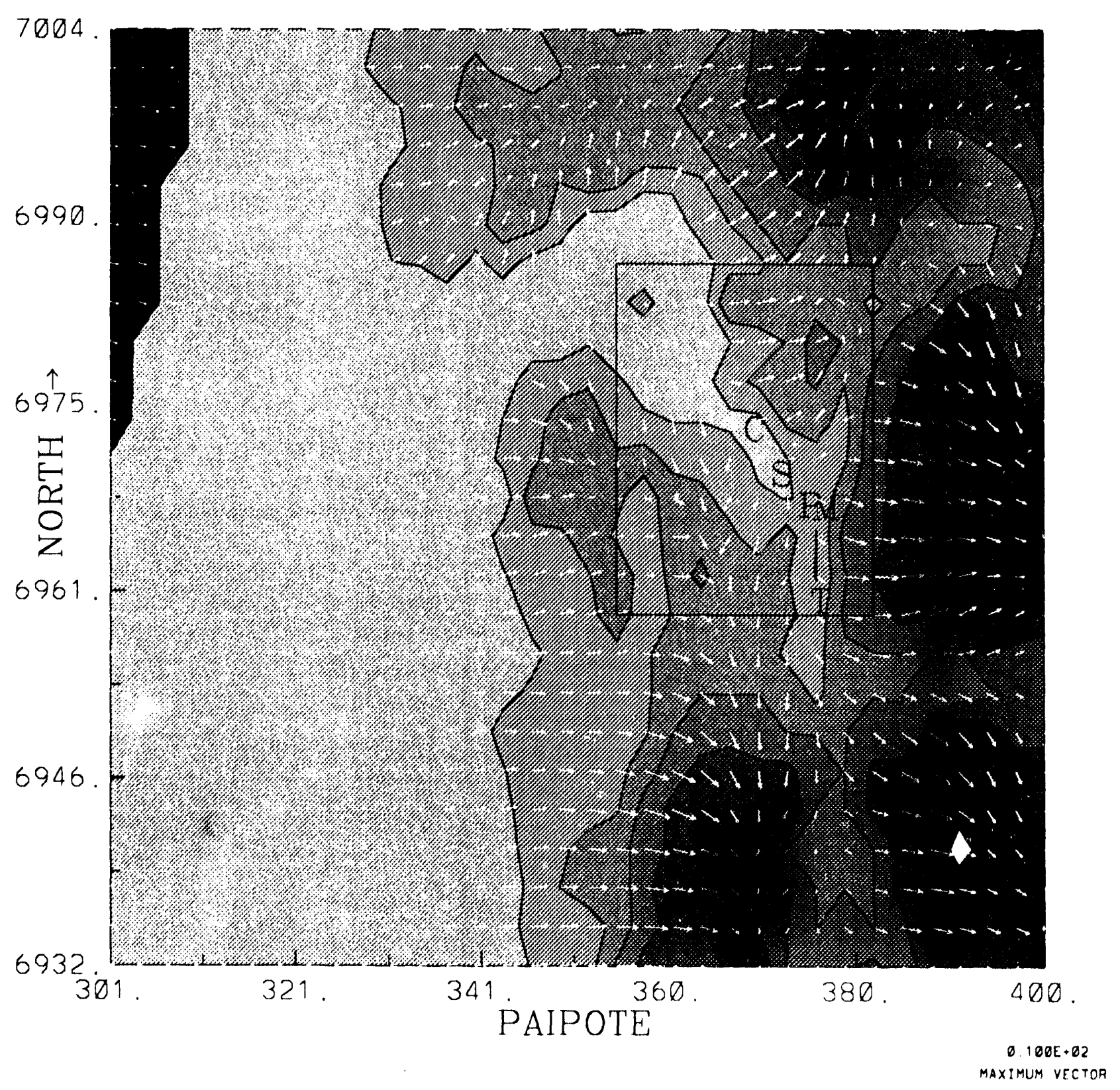

Figure EA. Simulated winds at noon on July 7, 1992 on the intermediate domain near Paipote. Symbols show monitoring station locations, while the box shows the fine grid domain. 


\section{JULY 19924 PM}

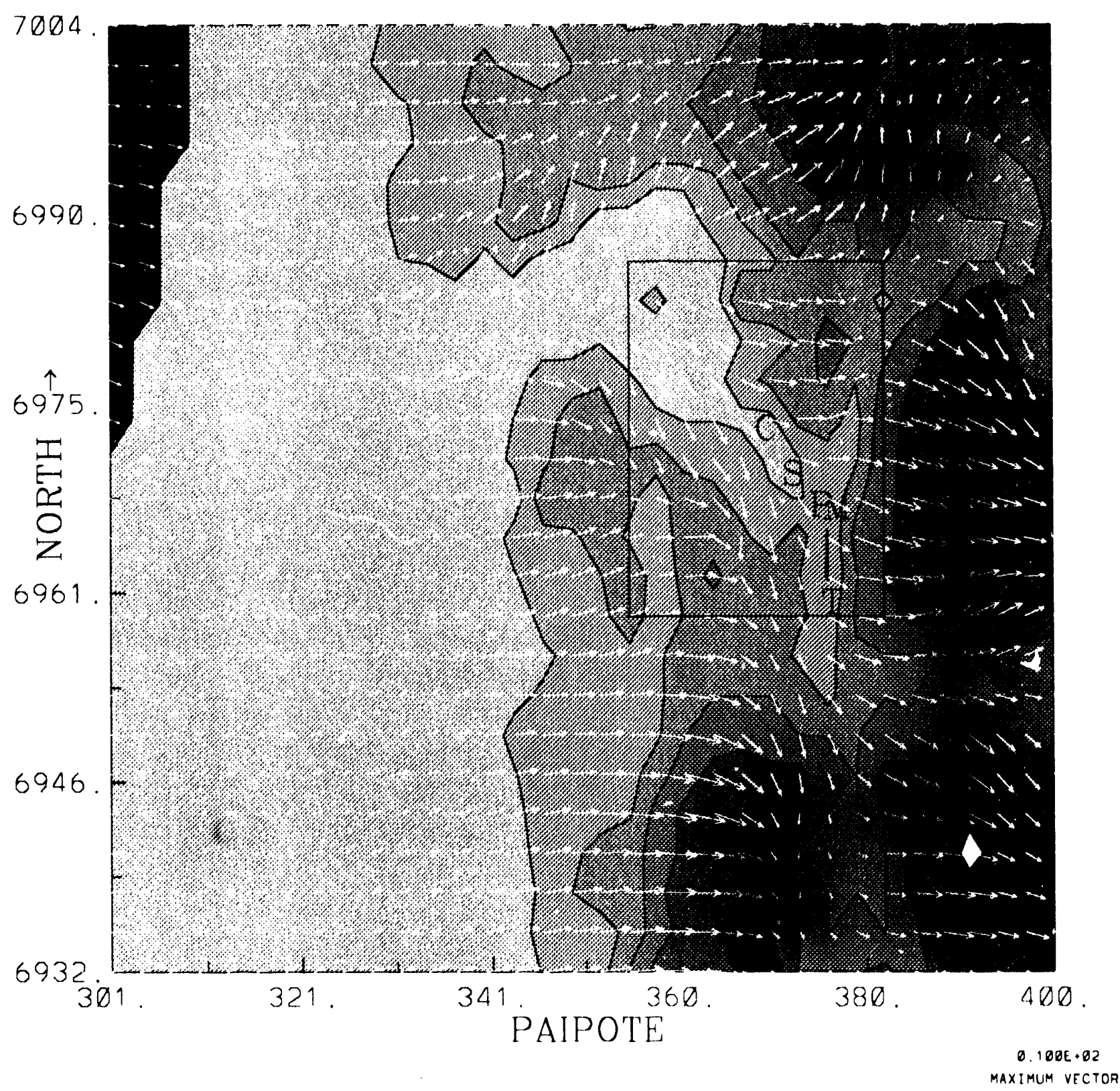

Figure E5. Simulated winds at 4 pm on July 7, 1992 on the ir:ermediate domain near Paipote. Symbols denote monitoring station locations an box defines fine grid domain. 


\section{JULY 19923 AM}

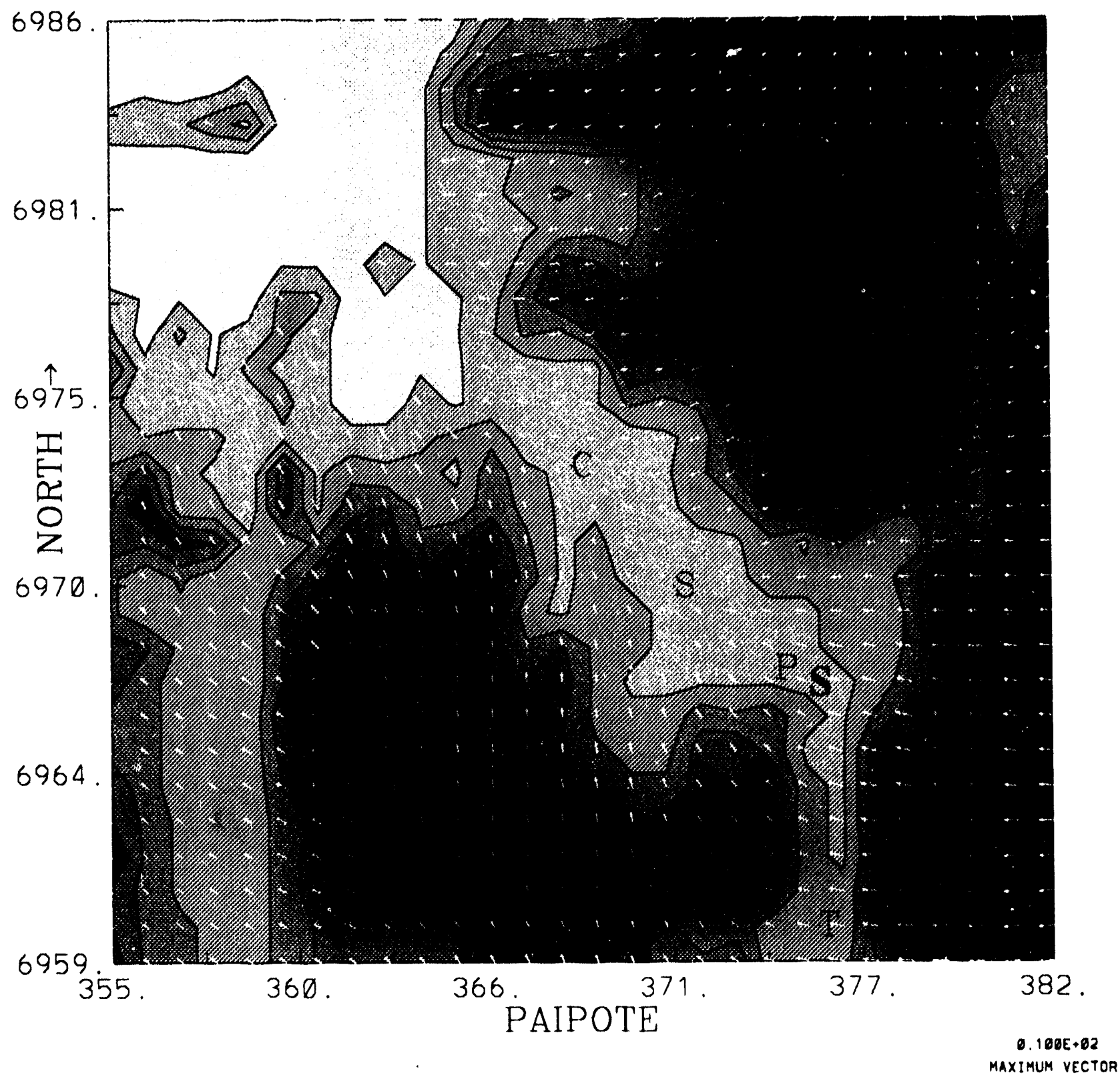

Figure E6. Comparison between simulated winds of the fine grid domain and measured winds (red arrows near symbols) at 3 am on July 7,1992 . S denotes the smelter stack location. 


\section{JULY 199212 PM}

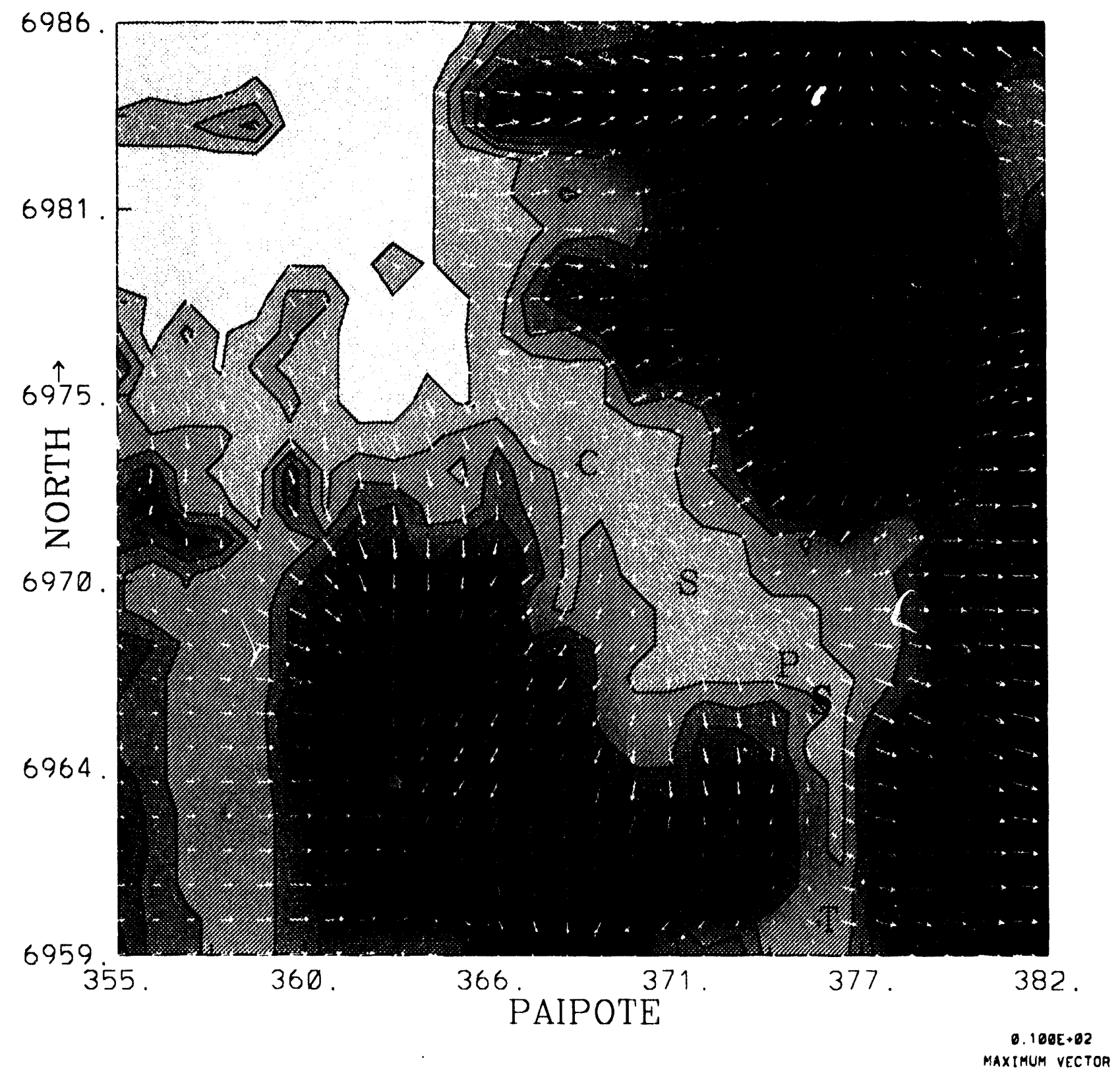

Figure E7. Comparison between simulated winds on the fine grid domain and measured winds (red arrows near symbols) for noon on July 7, 1992. S denotes smelter stack location. 


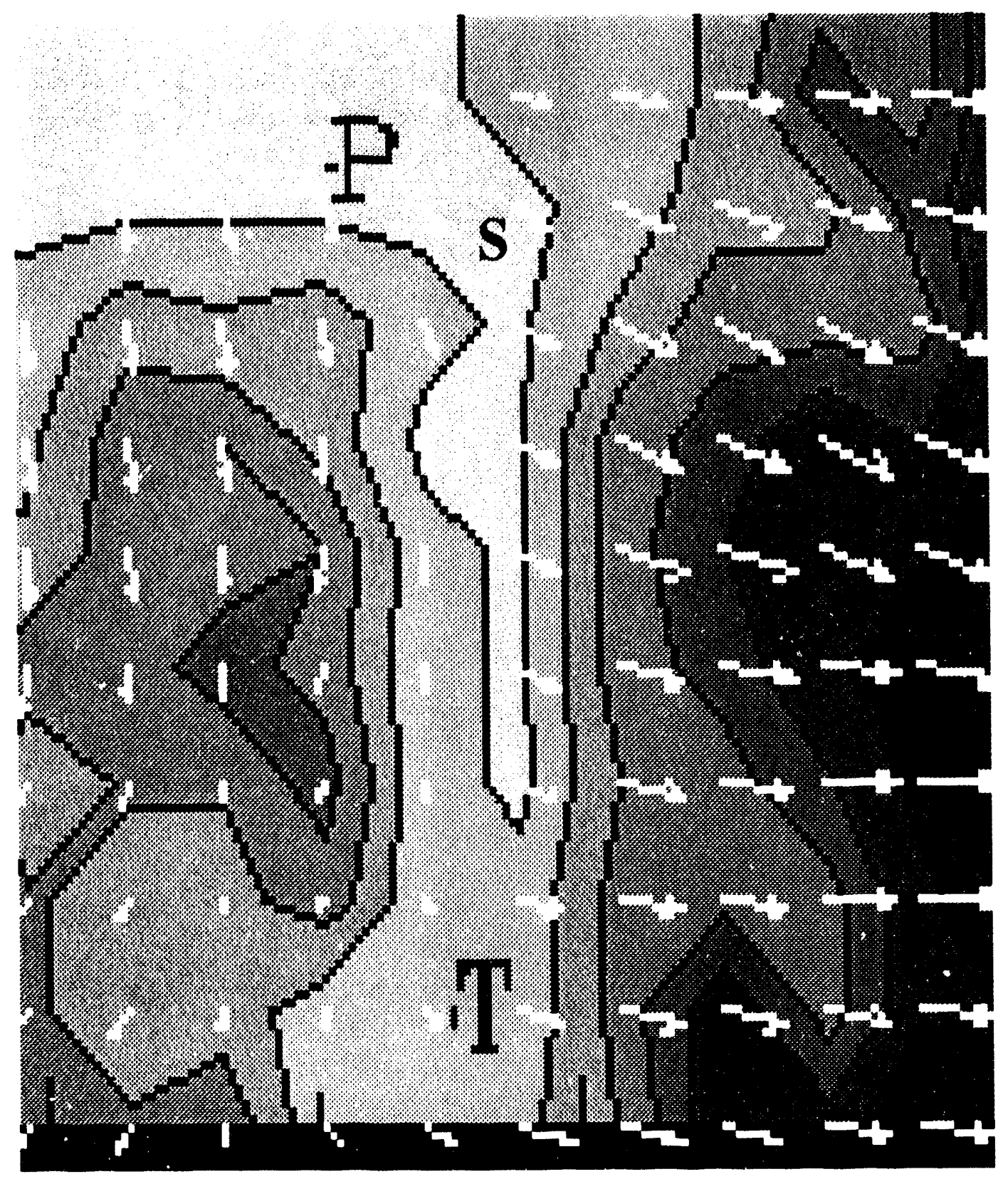

Figure E8. Winds and Topography in the vicinity of the source $(\mathrm{S})$ and the Paipote $(P)$ and Tierra Amarilla $(T)$ stations, July 7 at noon. 


\section{JULY 19924 PM}

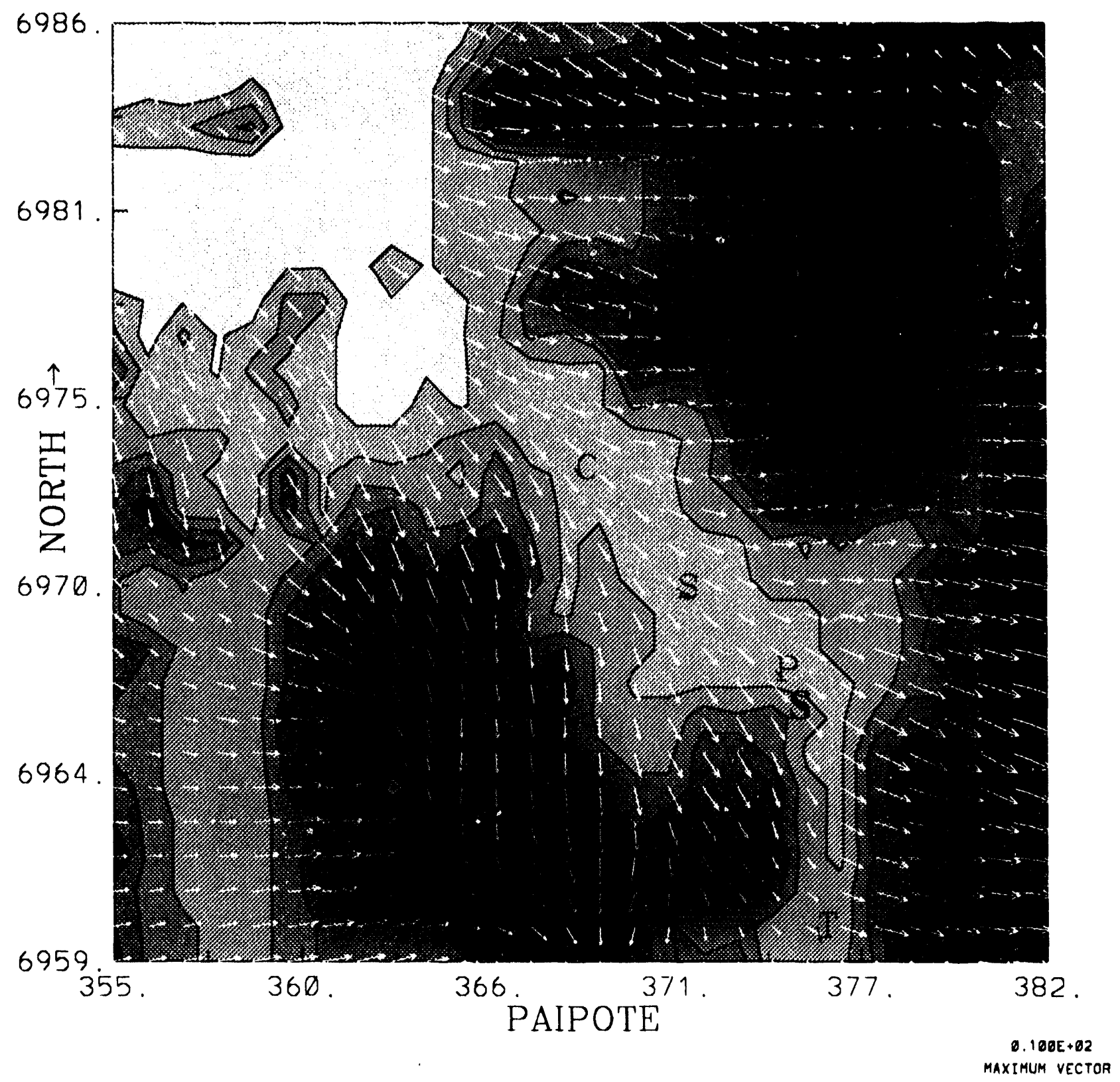

Figure E9. Comparison between simulated winds on the fine grid and measured winds (red arrows near symbols) for 4 pm on July 7,1992. 


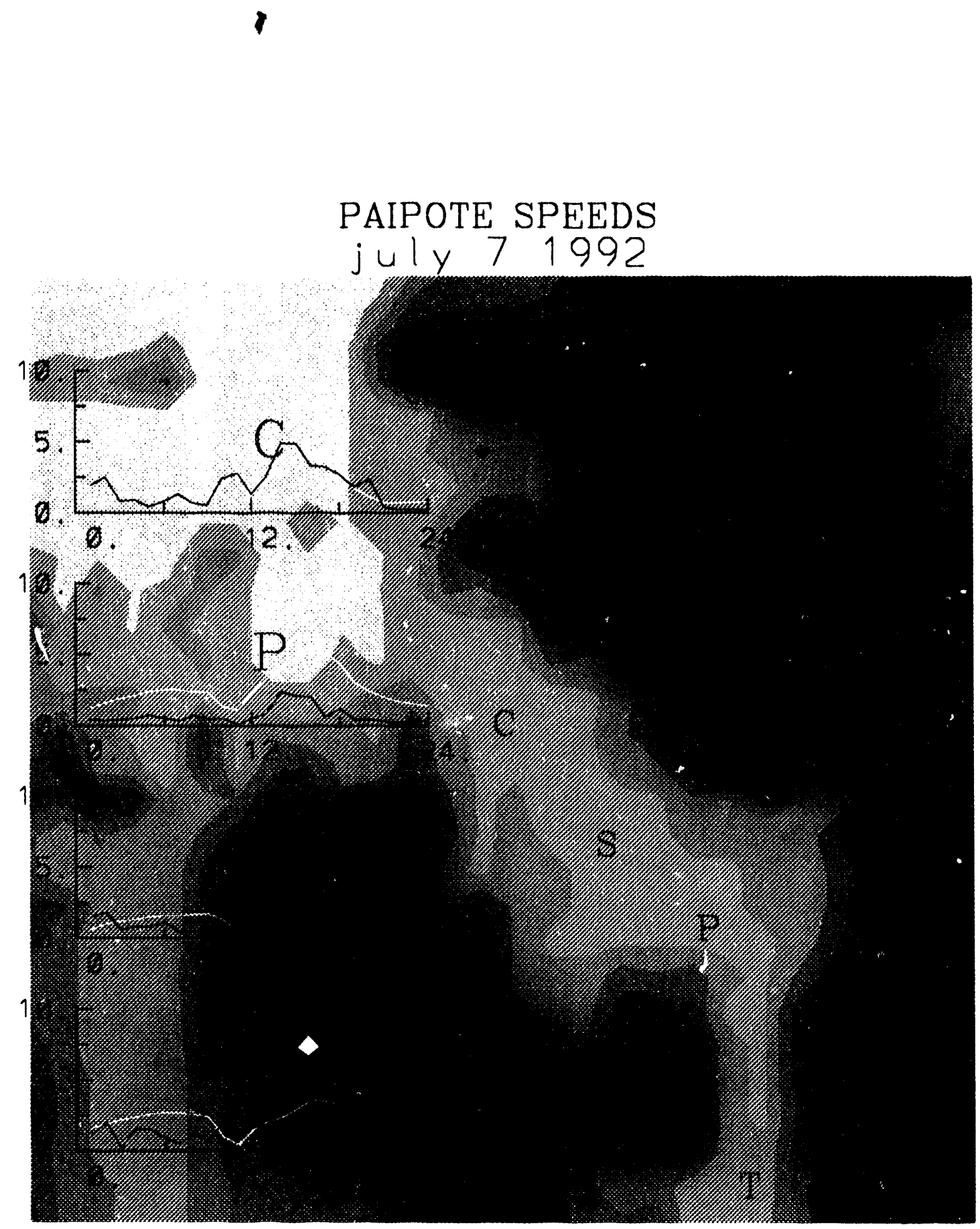

Figure E10. Comparison between simulated and measured hourly winds speeds $(\mathrm{m} / \mathrm{sec})$ on July 7,1992 near Paipote. 


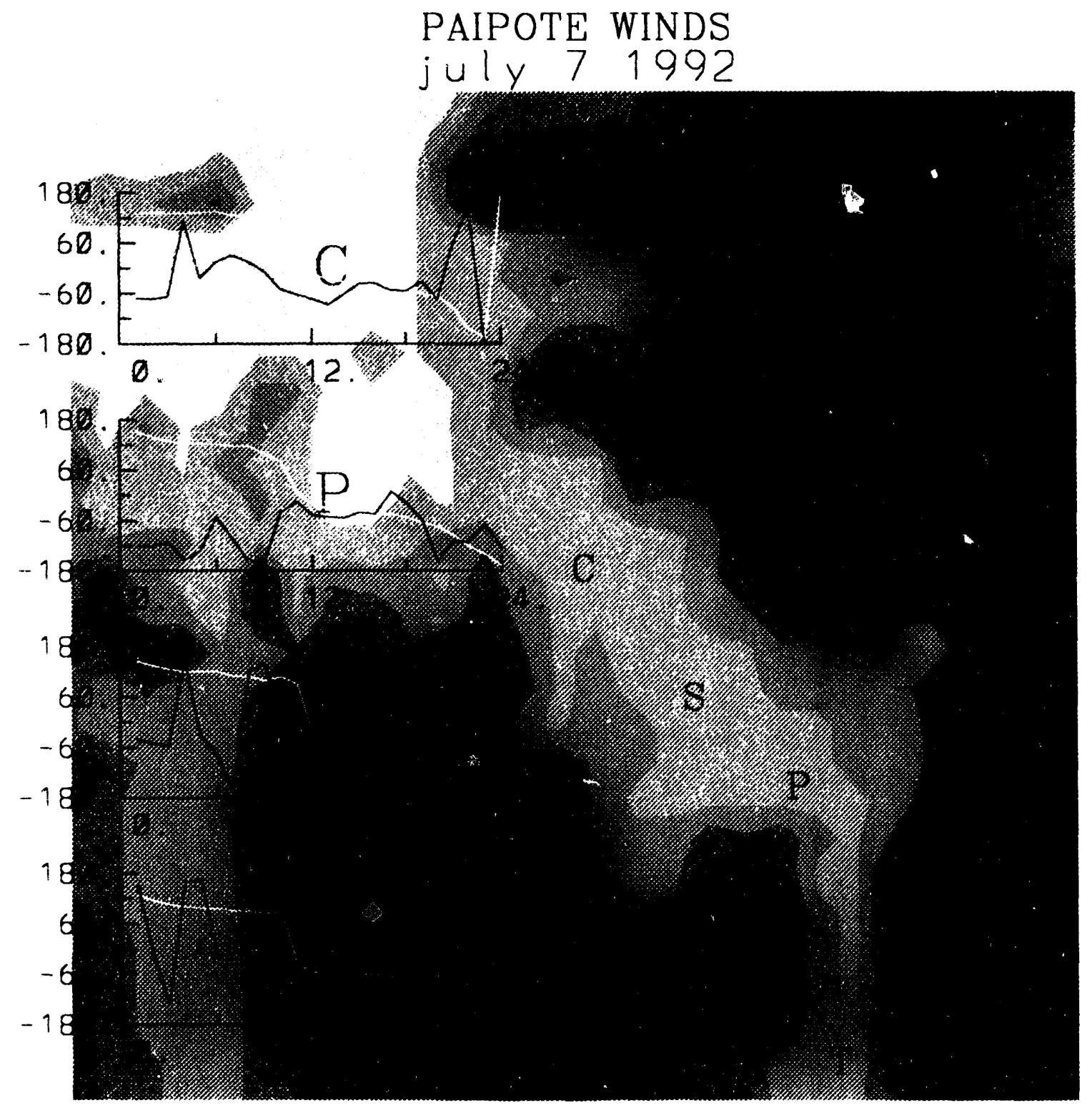

Figure E11. Comparison between hourly measured wind directions and modeled wind directions for July 7, 1992 for stations near Paipote. 


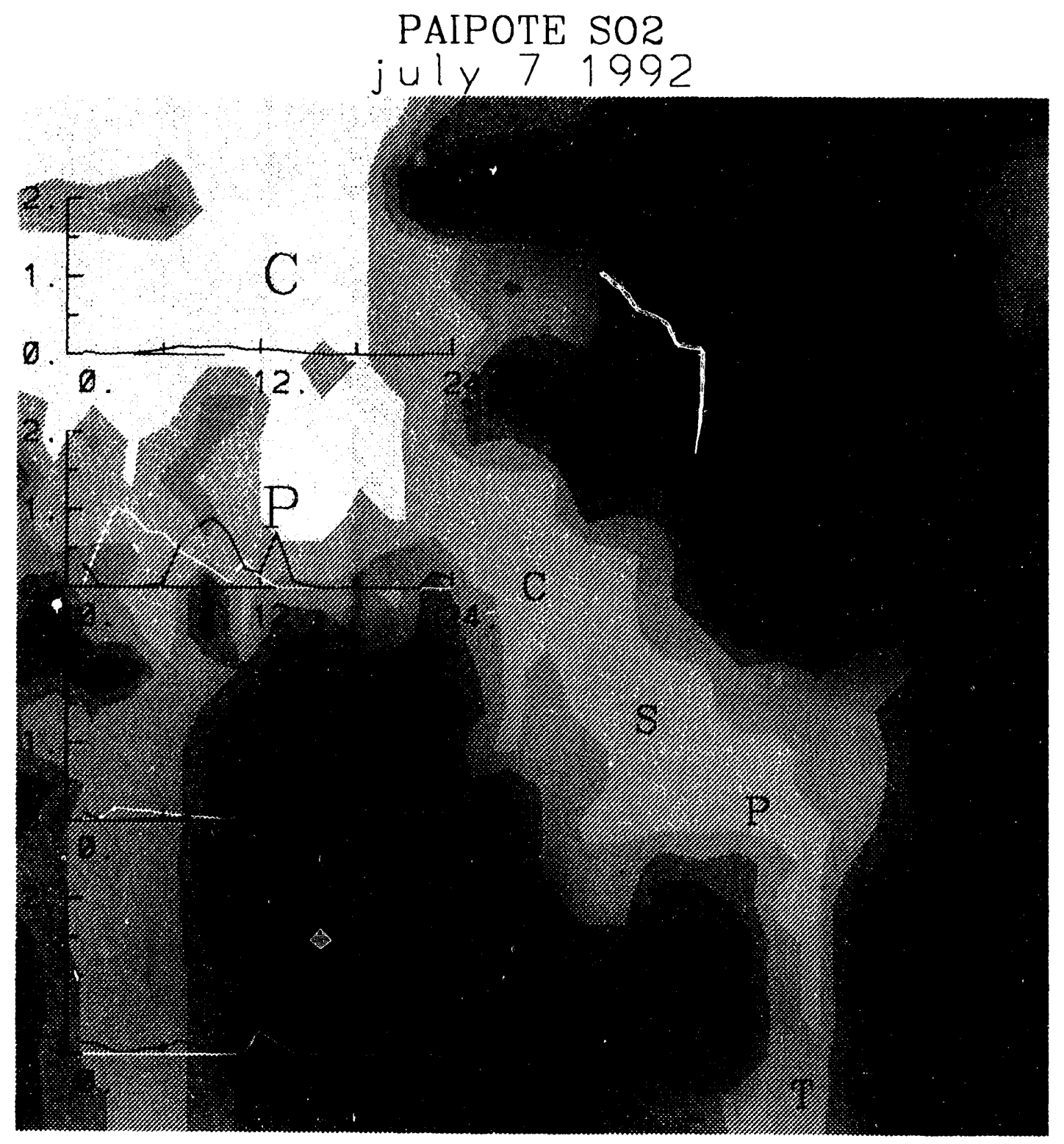

Figure E12. Comparison between modeled and measured hourly sulfur-dioxide concentrations for July 7, 1992 at stations near Paipote. 


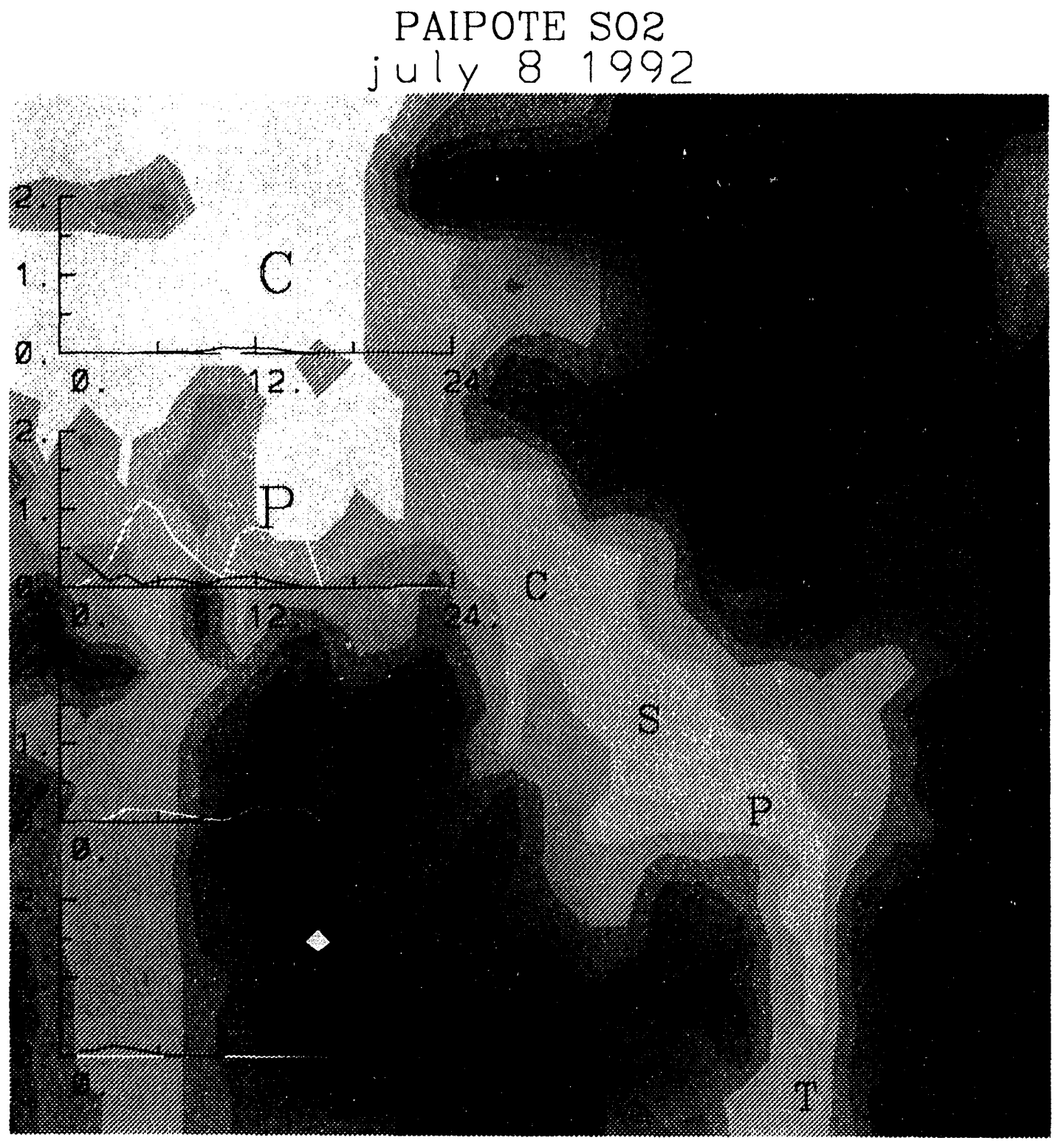

Figure E13. Comparison between hourly modeled and measured sulfur-dioxide concentrations (in parts per million) on July 8, 1992 at stations near Paipote. 

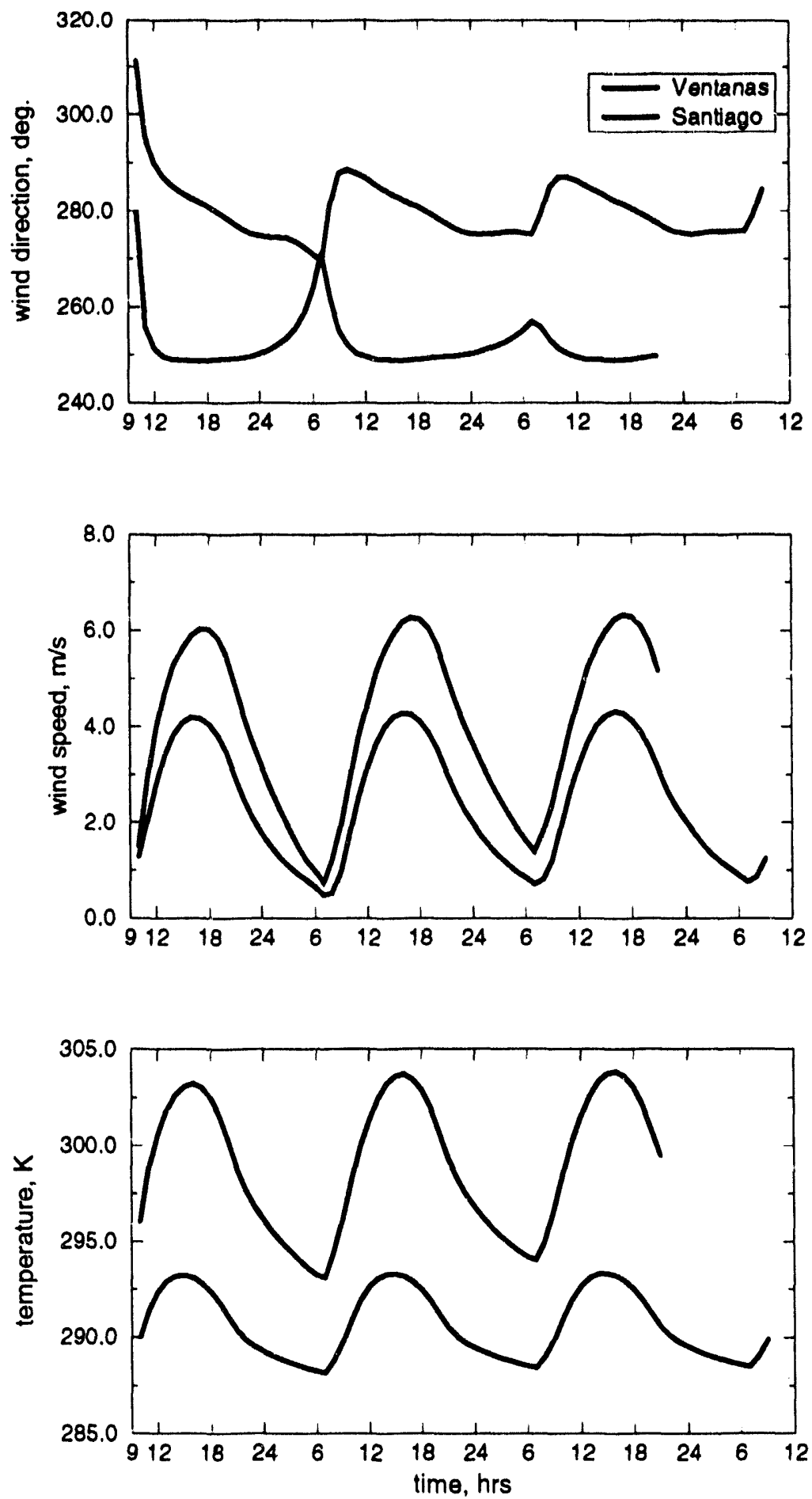

Figure F1. Time series profiles of wind direction, wind speed, and temperature produced by the HOTMAC model for the case with no large-scale forcing. Measurements at Ventanas and Santiago at a height of ten meters. Simulation start time: 8:00 am. Dec. 10. 

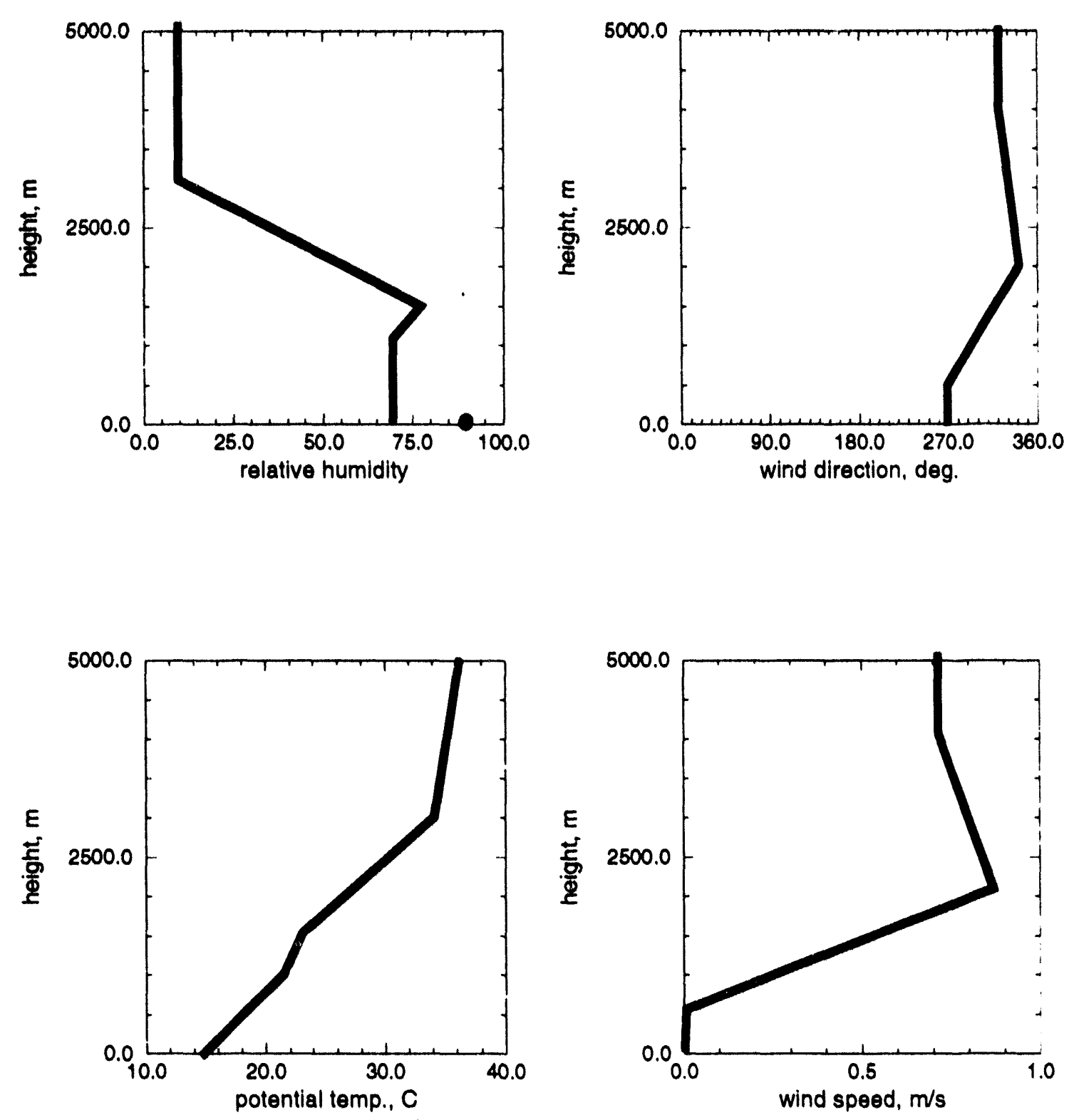

Figure F2. Initial profiles of relative humidity, potential temperature, wind speed, and wind direction used as input for the HOTMAC simulations. Profiles derived from Quinteros upper air measurements taken at 8:00 am on Dec. 10. 1992. 


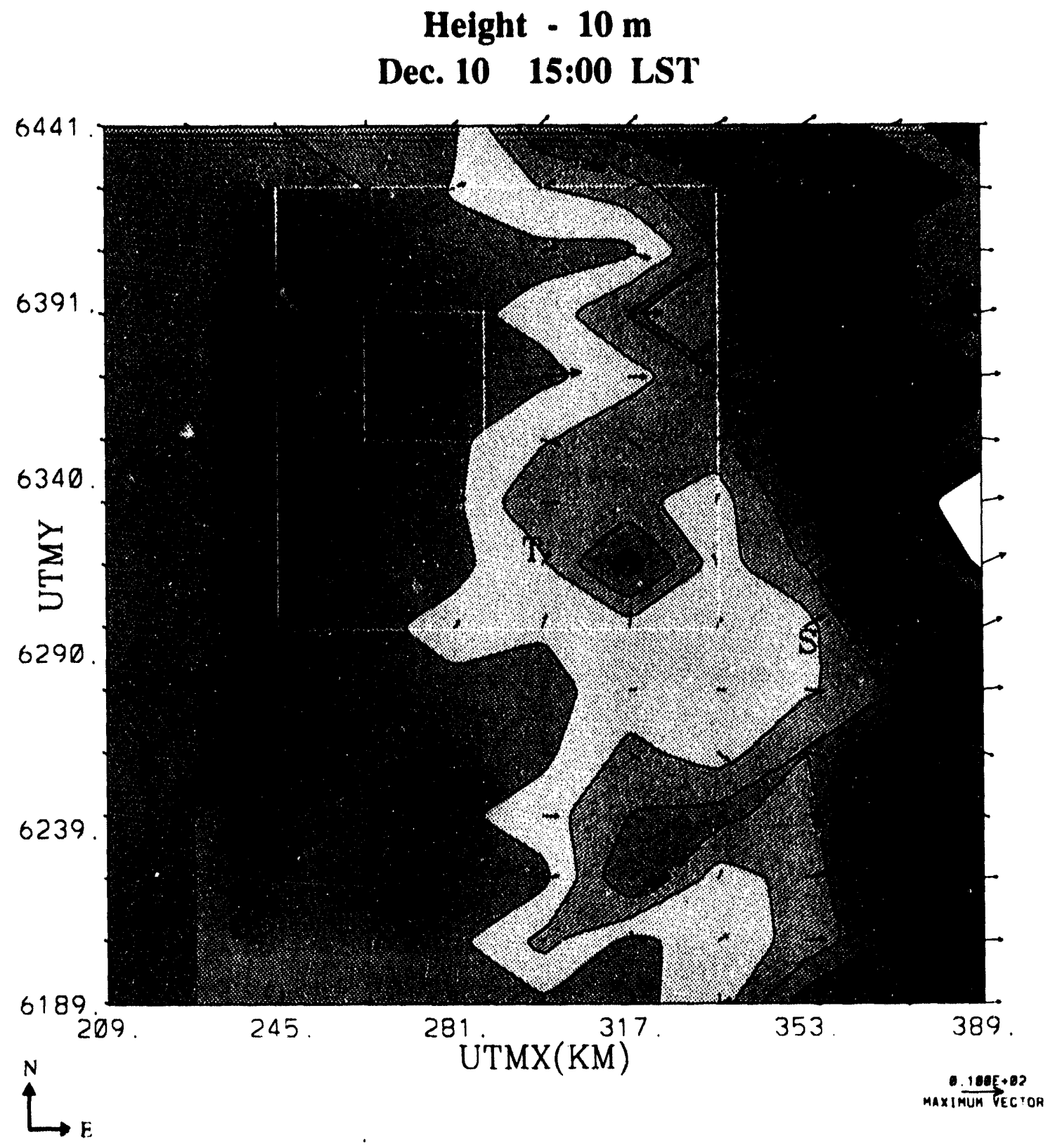

Figure F3. The modeled near-surface horizontal winds on the outer computational grid. Typical day time conditions. Yellow rectangles demarcate the location of the intermediate and inner computational grids. Letter designations: E - La Estrella, G - Guardia Vieja, O - occan site. Q - Quinteros, S - Santiago, T - El Trebolar, X Ventanas. Note: the topographical contours are interpolated from data on an eighteen kilometer grid. 


\section{Height $-10 \mathrm{~m}$ \\ Dec. 11 6:00 LST}

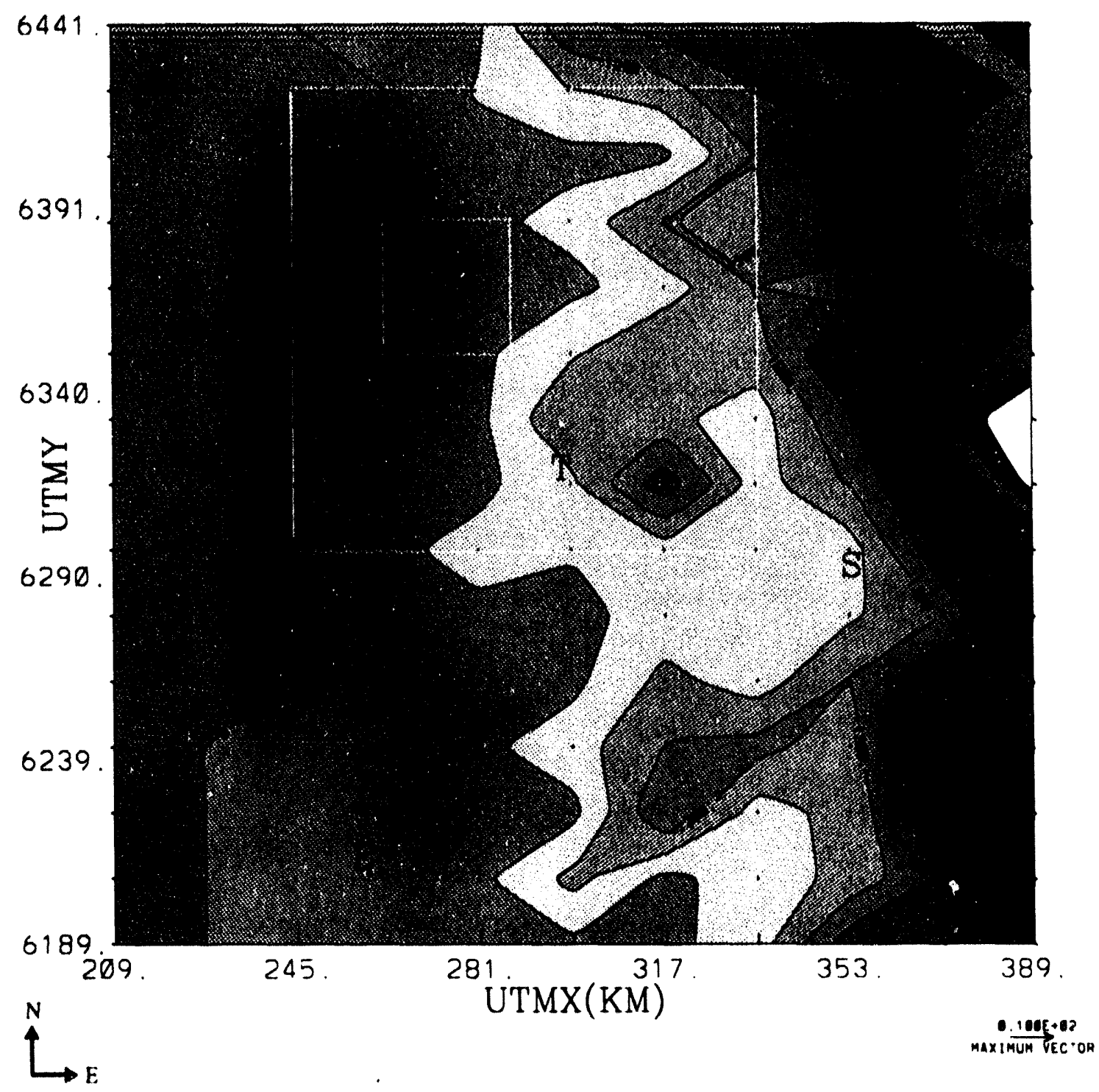

Figure F4. The modeled near-surface horizontal winds on the outer computational grid. Typical night time conditions. 


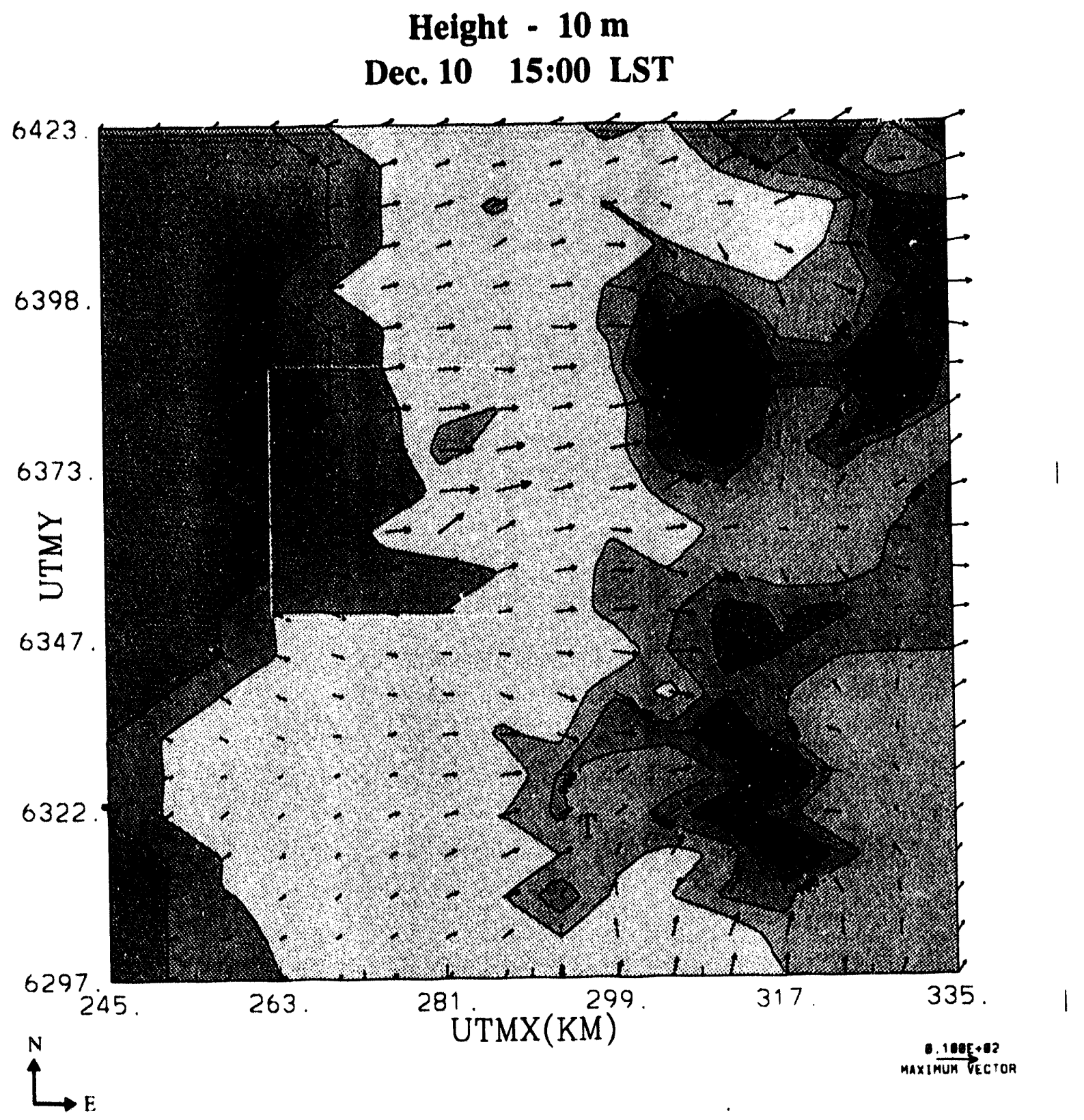

Figure F5. The modeled near-surface horizontal winds on the intermediate computational grid. Typical day time conditions. The yellow rectangle demarcates th: inner grid. Note: the topographical contours are interpolated from data on a six kilometer grid. 


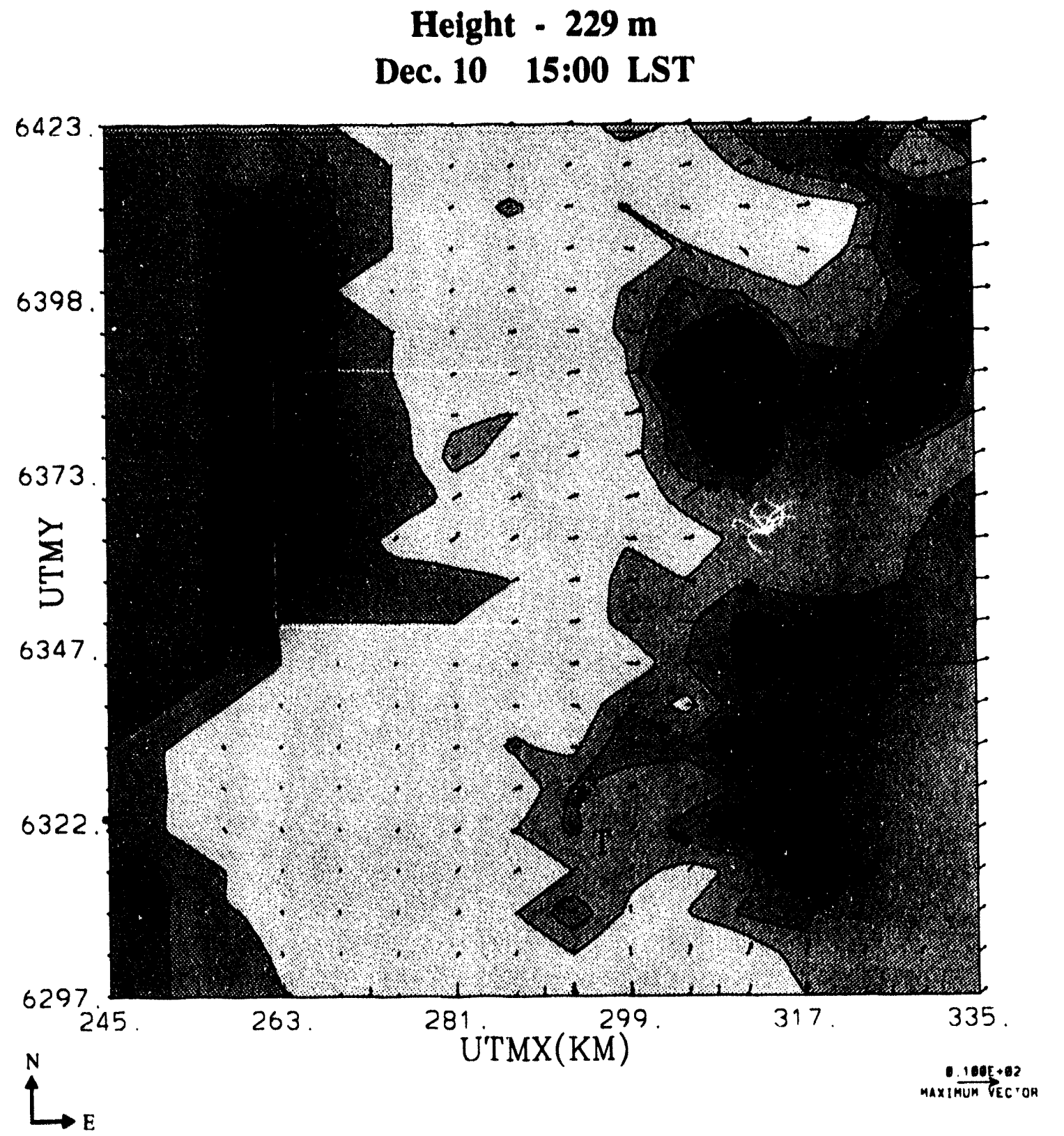

Figure F6. The modeled horizontal winds at $229 \mathrm{~m}$ on the intermediate computational grid. Typical day time conditions. 


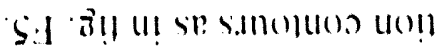

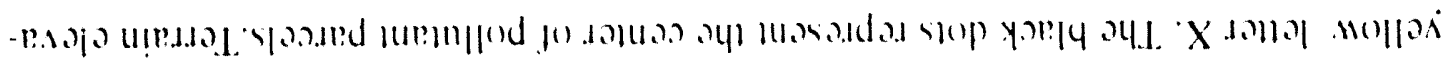

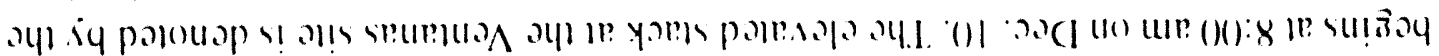

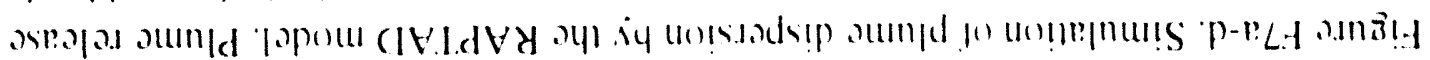
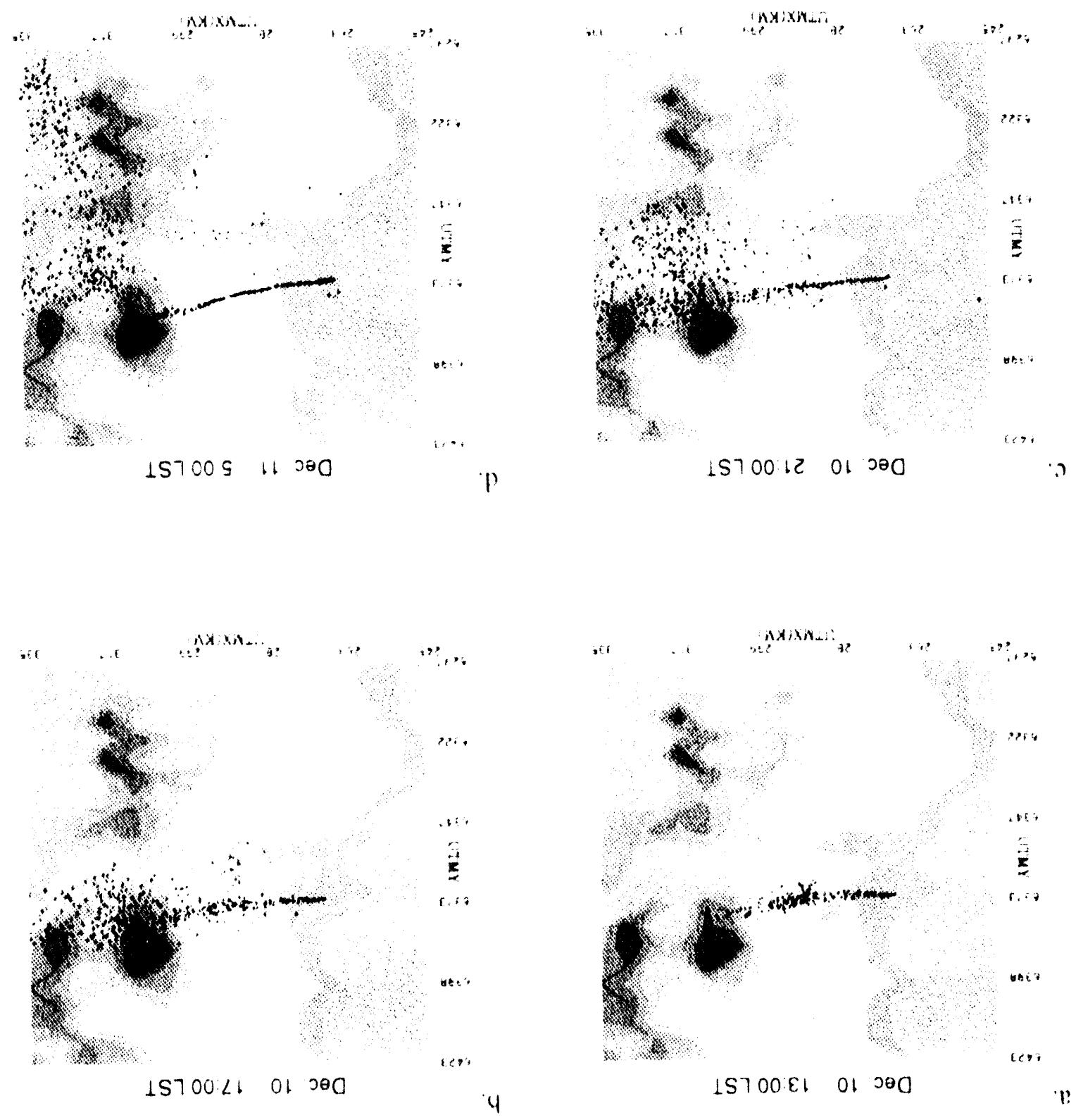

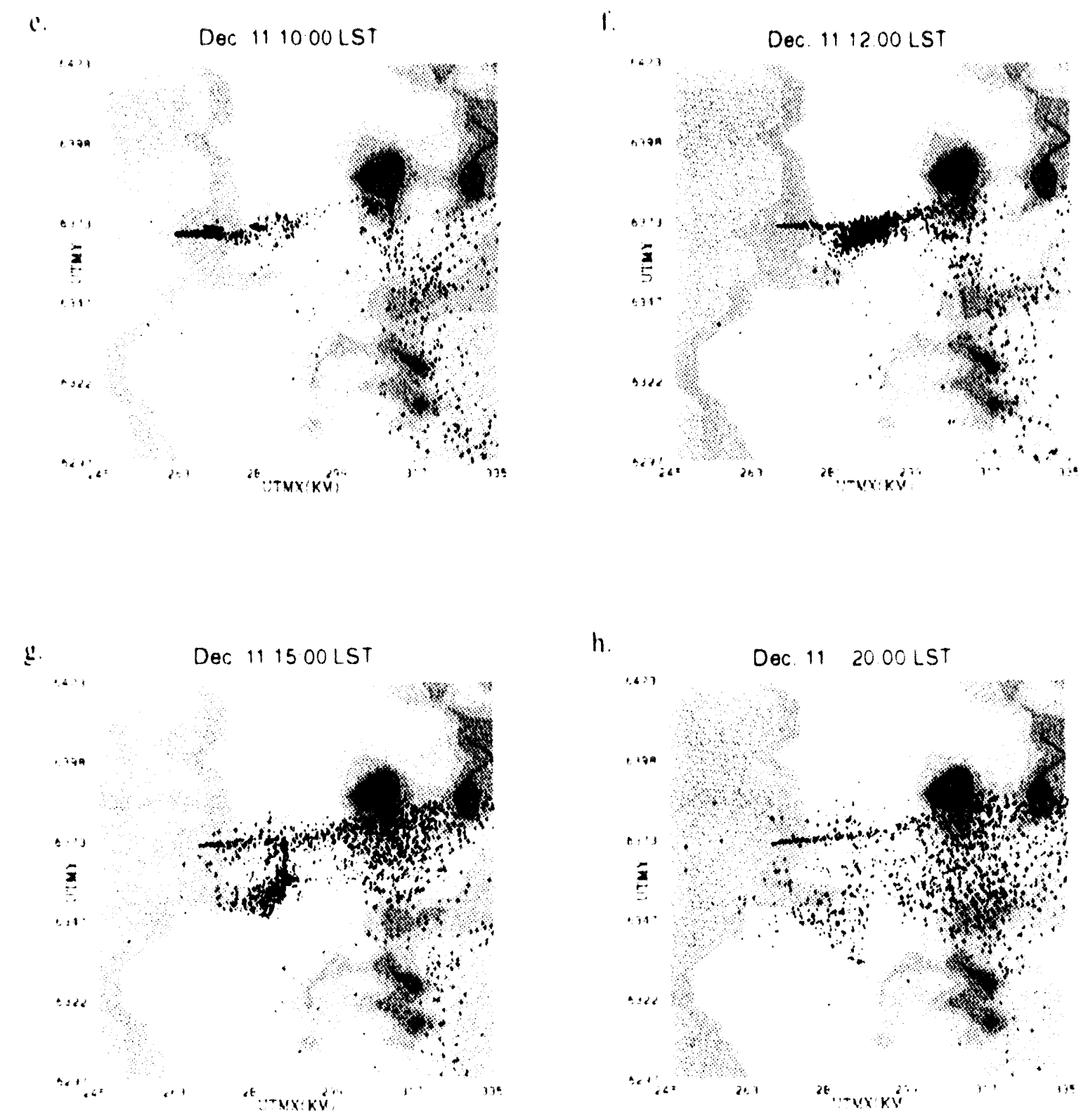

Figure 179 - 1 . Simulation of plume dispersion hy the RAPTAD model. Plume releate hegins at $8:(1)$ alm on Dece. 10. The elevated stack at the Ventanas site is denoted by the yellow letter $X$. The black dots represent the center of pollutant parcels. Terrain clevation contours as in lig. 1.5. 

